Revista lus et Praxis, Año 22, No 2, 2016, pp. 53 - 90

ISSN 0717 - 2877

Universidad de Talca - Facultad de Ciencias Jurídicas y Sociales

La naturaleza pluriofensiva y transnacional del fenómeno de la corrupción. Desafíos para el Derecho Penal Raúl Carnevali R. - Osvaldo Artaza V.

Trabajo recibido el 10 de marzo y aprobado el 1 de junio de 2016

\title{
La naturaleza pluriofensiva y transnacional del fenómeno de la corrupción. Desafíos para el Derecho Penal*
}

\author{
THE MULTIPLE OFFENSE AND TRANSNATIONAL NATURE \\ OF THE CORRUPTION PHENOMENOR. CHALlenges fOR CRIMINAL LAW
}

\author{
Raúl Carnevali R.** \\ Osvaldo ArTAZA V.
}

RESUMEN

El propósito de este artículo consiste en ofrecer un análisis de la potencialidad lesiva del fenómeno de la corrupción. En particular, se analizarán las consecuencias que en el plano económico conlleva la corrupción en un contexto globalizado. Para una mejor comprensión de dicho fenómeno se hará referencia a diversos instrumentos internacionales con el propósito de analizar una de sus expresiones más relevantes: la corrupción de funcionario público extranjero. Finalmente, dada su relevancia a nivel comparado, se analizarán las reglas contenidas en la Foreign Corrupt Practices Act norteamericana.

\section{ABSTRACT}

The purpose of this paper is to make an approach to the harmful potential of the phenomenon of corruption. In particular, we will delve into the consequences that corruption has in a global context. For a better understanding of this phenomenon, the article will make reference to various international instruments for the purpose of analyzing one of its most important expressions: the corruption of a foreign public official. Finally, in consideration of its special relevance, we will analize the rules contained in the American Foreign Corrupt Practices Act.

\section{Palabras Clave}

Corrupción, Globalización, Transacción económica internacional, Funcionario público extranjero, Foreign Corrupt Practices Act

\section{KEYWORDS}

Corruption, Globalization, International economic transaction, Foreign public official, Foreign Corrupt Practices Act

\footnotetext{
* Este trabajo ha sido realizado dentro del marco del Proyecto Fondecyt № 1150148, titulado "Corrupción y actividad empresarial. Análisis conceptual para una nueva sistematización". Los autores agradecen la colaboración de los ayudantes de investigación Sres. Sebastián Galleguillos Agurto y Luciano Rojas Morán.

** Profesor titular de la Universidad de Talca. Director del Centro de Estudios de Derecho Penal. Doctor en Derecho. Correo electrónico: rcarnevali@utalca.cl.

*** Profesor Asistente de la Universidad de Talca. Coordinador de extensión de Derecho Penal Económico del Centro de Estudios de Derecho Penal. Doctor en Derecho. Correo electrónico: oartaza@utalca.cl.
} 


\section{Introducción. Una descripción tradicional de los efectos asociados a la corrupción}

Como es sabido, los relatos policiales norteamericanos -la llamada novela negra- describen muy bien cómo la corrupción, en sus diversas manifestaciones, forma parte de la sociedad y va moldeando las relaciones humanas, sin distinción de clases sociales. Es más, generalmente estas novelas apuntan a cómo algunos, aprovechándose de fisuras institucionales y cierta tolerancia social, van construyendo su poder a través de la corrupción, conformando, asimismo, organizaciones criminales ${ }^{1}$. Al efecto podemos citar un diálogo que tiene lugar en el libro "El sueño eterno" de Raymond Chandler, publicado en 1939. Philip Marlowe le comenta a Vivian Regan, refiriéndose a una determinada persona: "Tenía antecedentes penales". Vivian le contesta: "No tenía las amistades adecuadas. Eso es todo lo que los antecedentes penales significan en este país podrido de crímenes" ${ }^{2}$.

Si bien el fenómeno de la corrupción es un problema universal y constante a lo largo de la historia ${ }^{3}$, probablemente está suscitando mayor atención en los últimos veinte años ${ }^{4}$. Basta tener presente que los principales instrumentos normativos de carácter internacional han sido dictados a partir de la pasada década del noventa. Por otra parte, tampoco puede asociarse, así sin más, que la corrupción es una especie de patrimonio de los países pobres o aquellos que viven bajo dictaduras. Por el contrario, numerosos son los casos de sociedades democráticas que enfrentan graves episodios de corrupción ${ }^{5}$.

En todo caso, sí debe tenerse en consideración que la diferencia esencial con regímenes autoritarios es que las sociedades democráticas disponen de mayores herramientas para enfrentar la corrupción 6 . Incluso no sólo desde una perspectiva puramente institucional, sino además por la presión que la propia ciudadanía impone a sus autoridades. En este sentido puede decirse que existe una mayor conciencia acerca de los riesgos que suponen para la propia sociedad las prácticas corruptas ${ }^{7}$. Valores públicos como la probidad y la transparencia comienzan a ganar espacio en el discurso ciudadano.

\footnotetext{
1 Balmaceda y Castro (2015), pp. 37-38.

2 Chandler (1990), p. 35.

3 Acerca de su evolución y una mirada desde la antigua Atenas, HefFernan y KleiniG, (2004), pp. 25 y ss.

4 TANZI (2002), pp. 19 y ss.

5 Sin ir más lejos, basta ver lo sucedido con la clase política brasileña, cuestionada, entre otros factores, por los sucesos de Petrobras. Para un análisis de la situación en la India y Brasil, YADAV (2011), pp. 57 y ss.

6 Alonso y Garcimartín (2011), pp. 45-46.

7 Zalaquett (2011), pp. 180 y ss., da cuenta de cómo a partir de los noventa va emergiendo la llamada good governance, dirigida a enfrentar la corrupción y fortalecer la democracia.
} 
Como señala Kindhäuser, la corrupción no debería ser entendida como un delito autónomo, sino que constituye una determinada forma de agresión con la que pueden vulnerarse los más distintos intereses penalmente protegidos ${ }^{8}$. Por lo general, cuando se habla de corrupción se estaría haciendo alusión a un concepto centrado en la infracción de deberes funcionariales a través del abuso del poder decisorio -usualmente asociados a la función pública-con el propósito de beneficiar indebidamente a quien infringe tal deber o a un tercero ${ }^{9}$.

Los efectos negativos que la corrupción puede generar son particularmente graves y de distinta naturaleza ${ }^{10}$. Al respecto, se ha puesto un mayor énfasis en la descripción y análisis de los efectos lesivos de la corrupción en el desarrollo de la función pública. En este ámbito, la corrupción socavaría y deslegitimaría el sistema democrático y la actividad política en general. Probablemente, esta es la consecuencia más grave, pues corroe la confianza ciudadana hacia las instituciones, no sólo públicas sino también privadas, pues en no pocos casos se suele señalar a las corporaciones privadas como las responsables de querer utilizar al aparato público en su beneficio. Un ejemplo de ello dice relación con el financiamiento de la política, donde los costos de las campañas, al ser cada vez más altos, exigen la introducción de medidas a fin de limitar intervenciones que puedan considerarse indebidas ${ }^{11}$. Basta tener presente lo expuesto por el Consejo asesor presidencial contra los conflictos de interés, el tráfico de influencias y la corrupción -la Ilamada Comisión Engel- en su informe final de abril de $2015^{12}$, donde una de sus propuestas se refiere, precisamente, al financiamiento de la política para fortalecer la democracia; es decir, establecer medidas para evitar la captura de la política para fines que son ajenos al interés público. En este sentido, se torna primordial, según expresas palabras del informe, "garantizar condiciones de equidad en la competencia electoral, para garantizar también el ejercicio de derechos civiles y políticos básicos"13.

\footnotetext{
8 Así lo expresa KindHäUSER (2007), p. 2.

9 Para un análisis conceptual del concepto de corrupción dentro del medio nacional véase ARTAZA (2016), pp. 307 y ss.

10 Holmes (2015), pp. 18 y ss.

11 Pelizzo y Stapenhurst (2014), pp. 83 y ss.; Álvarez (2007), pp. 39 y ss.

12 Ver en: http://consejoanticorrupcion.cl/wp-content/uploads/2015/06/2015.06.05-consejo_anticorrupcion.pdf.

13 Informe Comisión Engel, p. 65: "Por otra parte, las campañas son la expresión más nítida de la competencia política y están en la base de una democracia representativa. Por lo mismo, es fundamental garantizar condiciones de equidad en la competencia electoral, para garantizar también el ejercicio de derechos civiles y políticos básicos. En esta materia, el Consejo estima necesario mejorar las condiciones de equidad en la competencia -equilibrando los aportes públicos y privados-, disminuir los riesgos de captura de la política limitando aportes, mejorando las normas y capacidad de control. Finalmente, se
} 
Los riesgos de la corrupción para el sistema democrático y la pérdida de prestigio de las instituciones públicas se ven muy claramente en varios países de América Latina ${ }^{14}$. Es en esta región donde se aprecia una permanente inestabilidad política y constantes casos de corrupción en los que se ven involucrados, incluso, altos representantes del gobierno. Diversas son las razones que se pueden esgrimir para tan lamentable posición y que la sitúan muy por debajo de Europa o Norteamérica ${ }^{15}$. Entre otras, cabe citar la debilidad institucional de aquellas Ilamadas a ejercer el control de las cuentas públicas o de la actuación de los privados ${ }^{16}$. Ello puede deberse a un entramado normativo engorroso que dificulta la persecución, incentivando el abuso de poder. Así también, a una cultura tolerante hacia la corrupción, sobre todo cuando se requiere de servicios públicos (el soborno es una práctica extendida $)^{17}$.

La pérdida de confianza por parte de la ciudadanía hacia las autoridades públicas, más aún si se percibe una especie de cultura de la impunidad, resquebraja seriamente las bases del Estado de Derecho. Y es que se comienza a perder la fe en la democracia como sistema de gobierno ${ }^{18}$. Además, la debilidad institucional para perseguir los actos de corrupción funcionarial facilita el surgimiento de organizaciones criminales ${ }^{19}$. En efecto, si bien tales organizaciones no buscan ni pretenden alcanzar el poder político, sí se dirigen a controlarlo, conformando

propone modificar de manera significativa la forma en que se están realizando las campañas hoy, para reducir la escalada en el gasto y cambiar de una lógica centrada en la publicidad hacia otra centrada en ideas y producción programática".

14 Al respecto, Mulas-Granados (2011), pp. 105 y ss.; Morales Quiroga (2009), pp. 205 y ss. También se han visto casos graves de corrupción en Europa. Es así que la sociedad italiana fue testigo durante la década del noventa de importantes casos de corrupción -campaña llamada "Manos limpias"-, tanto pública como privada, en los que se vieron involucradas connotadas autoridades, algunas de ellas acusadas de connivencia con la mafia; BALMACEDA y CASTRO (2015), pp. 39 y ss.

15 En todo caso, en Italia la criminalidad organizada presenta conexiones cada vez más estrechas en el ámbito político, que le permite asegurar contratos con la administración pública. Un ejemplo es el caso del tratamiento de los residuos tóxicos, que genera cuantiosas ganancias (en Italia ya se habla de la 'ecomafia'). Sobre el punto, Plantamura (2007), pp. 73 y ss.; Lo Monte (2003), pp. 235 y ss.

16 Flores Giménez (2014), pp. 179 y ss.

17 Mulas-Granados (2011), pp. 113 y ss., expone una serie de gráficos que dan cuenta del recurso frecuente a la práctica del soborno en varios países de la región. Para un estudio acerca de la relación entre educación y niveles de corrupción, SANZ et al. (2011), pp. 131 y ss.

18 Rose-Ackerman (1999), pp. 127 y ss.; Díaz y García Conlledo (2007), pp. 122-125. Para conocer cómo han sido los procesos en las economías "transicionales", esto es, aquellas que pasaron del régimen socialista al capitalista, y de qué forma han enfrentado la corrupción, HaLLER y SHORE (2005), pp. 29 y Ss.; Abed y Davoodi (2002), pp. 489 y ss.

19 Carnevali (2014), pp. 65-66; Laudati (2003), p. 217: "El crimen organizado constituye un peligro para las democracias modernas por la extraordinaria capacidad de acumular enormes riquezas y de 
una especie de poder en la sombra. En este contexto, se constituyen en una fuente de corrupción de funcionarios públicos, con graves consecuencias para la legitimidad de las instituciones estatales, pues en los ciudadanos se genera una fuerte percepción de inseguridad pública. De más está decir los peligros que representan para un Estado estas organizaciones, ya no sólo desde la perspectiva de la seguridad ciudadana, sino también para la transparencia de las economías nacionales, pues uno los objetivos perseguidos es "intervenir" en el sistema económico lícito con el propósito de ir lavando sus activos, lo que puede dar lugar a una grave alteración de las reglas del mercado ${ }^{20}$. Lamentablemente, no son pocos los países latinoamericanos en donde se aprecia lo anterior ${ }^{21}$.

En este sentido, se pueden producir peligrosas relaciones entre dos importantes fuentes de poder, a saber: el económico y el político. De esta manera, según Ferrajoli, se manifestaría una expresión de criminalidad del poder, a través de la apropiación de la cosa pública, dando lugar a una clara desviación de orden institucional. El Estado se configura en un doble Estado, detrás de la fachada de legalidad crece y se desarrolla un infraestado clandestino, con códigos distintos y organizado en torno a centro de poderes ocultos. El riesgo evidente es que se produce una convivencia entre el aparato público y los grupos económicos, pues estos últimos se valen del aparato público para la consecución de sus objetivos. Tiene lugar una especie de apoderamiento privado de la cosa pública ${ }^{22}$.

De presentarse lo anterior, se puede comenzar a afirmar que se está frente a una captura del Estado, en el entendido de que individuos, empresas o grupos, al aprovecharse de sus contactos o asociaciones ilícitas, obtienen ganancias o facilitan actuaciones que a otros particulares no les serían permitidas. Tiene lugar una colusión particular entre lo público -ya sea funcionarios, legisladores o políticos- y los privados en que se definen políticas públicas, se obtienen ventajas contractuales, favoreciendo de este modo sólo a unos pocos, alterando las reglas de igualdad entre quienes intervienen en una determina actividad ${ }^{23}$. En definitiva, quienes detentan funciones públicas actúan favoreciendo sólo a quienes están dispuestos a pagar.

contaminar y condicionar las instituciones"; Sánchez García de la Paz (2008), p. 456; Castresana (2004), pp. 213 y ss.

20 Entre otros, Fernández (2000), p. 90; Szczaransky (2000), pp. 48-52; Castaldo y Naddeo (2010); Di NiCOLA (2002), p. 276.

${ }^{21}$ Al respecto, Solís y Rojas (2008), pp. 110-114.

22 Ferrajoli (2009), pp. 149-150.

23 Así lo exponen RodríGuez y OSSANdón (2008), pp. 58-59, quienes afirman que la corrupción pública modifica las reglas del juego, al dar lugar a una desigualdad oculta y mecanismos que son perversos para el desarrollo. 


\section{Corrupción y afectación de interés económicos}

Con todo, y como se pretende demostrar a continuación, el análisis de los efectos lesivos de la corrupción no debiera limitarse a los relativos a la función pública. Una breve descripción del panorama internacional permite constatar que este fenómeno podría afectar intereses o expectativas de enorme relevancia en el ámbito de los negocios y la economía ${ }^{24}$. Para dar cuenta de tal realidad se debiera considerar los diversos instrumentos internacionales que regulan esta materia, así como la tendencia internacional de ampliar la prohibición de los actos de corrupción en los casos en que ésta pueda poner en entredicho intereses económicos tanto públicos como privados.

Es importante tener en cuenta que cierta doctrina ha sostenido que bajo determinadas circunstancias económicas, y para impulsar el crecimiento, deberían aceptarse algunas manifestaciones de corrupción, pues de algún modo permitirían "lubricar" la maquinaria burocrática y, con ello, agilizar la economía. Es lo que habría sucedido en el sudeste asiático, en países como Indonesia o Tailandia, que a fines de los noventa crecieron rápidamente, aun cuando tenían altas tasas de corrupción ${ }^{25}$. Sin embargo, esta opinión es difícil de aceptar. En forma más reciente se ha dicho que, aun cuando es cierto que este fenómeno podría traer ciertos efectos positivos en el corto y mediano plazo, los efectos en la economía serían "devastadores" en el largo plazo ${ }^{26}$.

Por lo mismo, resulta erróneo defender, sobre la base de tales supuestos beneficios económicos que se pudieran reportar, que la corrupción pueda generar efectos positivos. Por el contrario, hoy se aprecia una mirada crítica hacia este fenómeno por las consecuencias negativas que conlleva. Es más, se puede decir que una de las particularidades de las sociedades modernas es la incidencia que ha tenido este fenómeno.

Esta apreciación se ha ido acentuando a partir de los años noventa, sobre todo con el desarrollo de la llamada globalización ${ }^{27}$. En efecto, la mayor libertad, y, por ende, los menores controles estatales para la circulación de estos factores, brinda enormes espacios de actuación a la corrupción ${ }^{28}$. En este sentido, los Estados han restringido sus limitaciones comerciales, dando lugar a una ampliación de los mercados. En particular, en la consecución de este

24 Entre otros, Soto (2003), pp. 23 y ss.; Aidt (2003), pp. 632 y ss.; Seligson (2006), pp. 381-404; Stein, pp. 61-81; Balmaceda y Castro (2015), pp. 57 y ss.; Rodríguez (2004), p. 345.

25 Al respecto, Braguinsky (1996), pp. 14 y ss.; Tanzi (2002), pp. 42-45; Gómez (2007), pp. 79-80.

26 BENITO (2012), pp. 43-44.

27 Gómez (2007), pp. 69-71; Bautista (2014), pp. 119 y ss.; Sánchez (2010), p. 212.

28 Johnston (2014), pp. 186-189; Shore y Haller (2005), p. 9. 
propósito se han impulsado a escala global una serie de políticas dirigidas a facilitar la libre circulación de determinados factores productivos, como, por ejemplo, los capitales, las mercancías, las personas y los servicios.

Precisamente, esta mayor laxitud en los controles, así como las asimetrías que tienen lugar entre los Estados, no sólo desde la perspectiva jurídica sino también cultural -la mirada y el juzgamiento moral hacia la corrupción es diverso entre las distintas naciones-, pueden propiciar las prácticas corruptas, pues los agentes van a preferir aquellas economías que brindan mayores escudos protectores $^{29}$. De este modo, la corrupción se constituye en un factor decisorio más a la hora de enfrentar una nueva oportunidad de negocios.

Tal realidad ha derivado en una mayor preocupación en la prevención de la corrupción en el ámbito de las interacciones económicas, debido a los efectos negativos que derivarían de tales prácticas. En este sentido, basta tener en consideración las distorsiones del mercado que se producen cuando compiten agentes carentes de toda ética, al pretender participar sin seguir las reglas del juego previamente impuestas. Riesgos que se acrecientan si para dicho propósito se utiliza a funcionarios públicos, ya que se constataría un evidente fracaso del servicio público como institución y una traición a la esencial ética profesional del funcionario público, el que no actúa como un agente de servicio al ciudadano. Las expectativas de imparcialidad en el trato con el Estado se verían seriamente erosionadas, pues se brindarían privilegios solamente a determinados actores económicos -los favorecidos por el soborno-, dando lugar a distorsiones competitivas y aumentando la ineficiencia en la asignación de recursos -no necesariamente se ofrecen los mejores servicios o productos-. Y es que, al no estar dadas las condiciones de igualdad, se pueden restar de intervenir otros que también están en condiciones de hacerlo ${ }^{30}$.

Es más, las reglas propias del mercado y de la competencia leal se ven fuertemente alteradas, ya que las empresas más pequeñas están incapacitadas de competir con las mayores, que ya disponen de recursos que les permiten intervenir en una economía corrupta ${ }^{31}$. Incluso, las consecuencias que se pueden dar son aún peores, pues al favorecer el surgimiento de una clase de economía más bien informal, al no poder intervenir en la formal, se eludiría el cumplimiento de los compromisos tributarios, con las derivaciones que todo ello supone ${ }^{32}$.

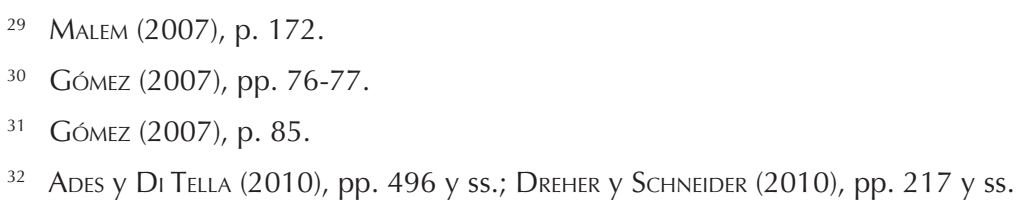


Por otro lado, economías que funcionan con una lógica corrupta, esto es, incumpliendo con las reglas básicas del mercado y con una cultura de los negocios en la que se procura obtener indebidamente ventajas, conlleva indefectiblemente consecuencias a nivel de inversión y de crecimiento. Y es que los inversores prefieren participar en aquellos países que les brinden seguridad y en los que no hayan "costos" asociados a corrupción ${ }^{33}$. En este contexto, no puede dejarse de tener presente que el fenómeno de la globalización -al que se aludió supra- ha procurado imponer una forma de hacer negocios, tanto en la esfera pública como privada, de manera que aquellos actos de corrupción que en el pasado podían ser de algún modo tolerados, hoy ya no se los aprecia de un modo similar.

En este breve examen de las consecuencias económicas de la corrupción no pueden obviarse dos cuestiones de particular relevancia: la pobreza y la inequidad $^{34}$. Y es que la desviación de fondos públicos destinados a la producción y a la inversión hacia patrimonios particulares afectará, indefectiblemente, la vida social, en especial a las personas con mayores carencias. Por otro lado, no puede dejarse de considerar que aquellas empresas que debieron pagar sobornos para poder realizar sus proyectos tratarán de algún modo de recuperar sus costos, ya sea por vía tributaria -lo que incide en la inversión pública- o pagando menos a sus trabajadores. A la larga las consecuencias se pueden hacer sentir en el crecimiento del país, en el nivel de empleo y en los precios de los productos ${ }^{35}$.

Tales valoraciones explicarían que se haya reconocido la necesidad de reaccionar frente a tal fenómeno asumiendo su naturaleza pluriofensiva. Lo anterior resulta claro si se considera el tratamiento normativo de la prohibición de la corrupción en los diversos instrumentos internacionales que regulan la materia. Como se hizo presente supra, a partir de la década de los noventa se suceden una serie de cuerpos normativos internacionales sobre corrupción, que imponen obligaciones incriminatorias a los Estados que los suscriben ${ }^{36}$. En lo que nos atañe son tres los más importantes, a saber: la Convención sobre la corrupción de 2003, de las Naciones Unidas; la Convención sobre la lucha contra la corrupción de los funcionarios públicos extranjeros en las transacciones comerciales internacionales de 1997, en el marco de la OCDE, y la

\footnotetext{
33 Para una relación entre corrupción e inversión, TANZI y DAVOODI (2002), pp. 197 y ss.; MAURO (1997), pp. 104 y ss.; MURIEL (2004), pp. 27 y ss.

34 Gupta et al. (2002), pp. 458 y ss.

35 Muriel (2004), pp. 35 y ss.; Alonso y Garcimartín (2011), pp. 66 y ss.; Gómez (2007), p. 84.

36 Así, Rodríguez y Ossandón (2008), pp. 70 y ss., quienes en pp. 82 y ss. exponen el tratamiento del Derecho chileno a la corrupción; Montanari, (2012), pp. 1 y ss. Disponible en: http://www.penalecontemporaneo.it/upload/1341134726Montanari\%20-\%20DPC.pdf.
} 
Convención interamericana contra la corrupción de 1996 de la Organización de Estados Americanos ${ }^{37}$.

En lo que se refiere a la Convención Interamericana contra la corrupción de $1996^{38}$, se disponen de medidas preventivas para enfrentar los actos de corrupción de los funcionarios públicos o por quienes ejerzan funciones públicas, así como también se refiere al soborno internacional y se incorpora la figura del enriquecimiento ilícito (art. IX) ${ }^{39}$. En este último caso, se pretende la inclusión como figura penal "del incremento del patrimonio de un funcionario público con significativo exceso respecto de sus ingresos legítimos durante el ejercicio de sus funciones y que no pueda ser razonablemente justificado por él"40. Precisamente, la influencia de la presente Convención determinó que en varios países de nuestro continente se introdujera el respectivo tipo penal ${ }^{41}$. En lo que respecta al objeto de estudio, este instrumento reconoce en su preámbulo que la lucha contra la corrupción puede evitar alteraciones en la economía. Con todo, sólo se regula la corrupción que tiene lugar en la administración pública, no haciéndose cargo aún de aquella que pueda tener lugar exclusivamente en el sector privado. Que así sea tampoco debe llamar la atención, pues, como se explicó, de esta manera se ha entendido tradicionalmente. Sólo en los últimos años ha habido una especial preocupación por lo que acontece en el mundo privado.

Posteriormente, en la Convención sobre la lucha contra la corrupción de los funcionarios públicos extranjeros en las transacciones comerciales internacionales de $1997^{42}$ se apunta a un tema en particular, a saber: el cohecho en las transacciones internacionales. En efecto, como ya se indica en el preámbulo, el

37 También pueden citarse, dentro de la Unión Europea, entre otras, la Convención relativa a la lucha contra la corrupción en la que estén involucrados funcionarios de las comunidades europeas o de los Estados miembros, de 1997, Acción Común 98/742 JAI sobre corrupción en el sector privado y la Decisión Marco 2003/568 JAI acerca de la lucha contra la corrupción en el sector privado. Dentro del Consejo de Europa, la Convención penal sobre corrupción de 1999 y el protocolo adicional de 2003. Por último, la Convención contra la criminalidad organizada transnacional de 2000, mejor conocida como la Convención de Palermo. Para un examen conjunto, Alcale Sánchez (2014), pp. 25 y ss.

38 Ver la Convención en http://www.oas.org/juridico/spanish/Tratados/b-58.html. Al respecto, Rodríguez y OSSANDÓn (2008), pp. 73-77.

39 La Convención americana constituyó un importante antecedente para las modificaciones introducidas respecto de los delitos cometidos por funcionarios públicos por la ley $\mathrm{N}^{\circ} 19.645$ de 11 de diciembre de 1999. Sobre el punto: Oliver (2004), pp. 83 y ss.

40 Al respecto, De la Cuesta Arzamendi (2003), pp. 13-14; Rodríguez (2004), pp. 357 y ss.

41 Hernández (2010), pp. 187 y ss., quien también expone la evolución experimentada por el Derecho chileno para introducir la respectiva figura del art. 241 bis del Código Penal.

${ }_{42}$ Ver la Convención en: http://www.oecd.org/daf/anti-bribery/ConvCombatBribery_Spanish.pdf. 
cohecho en las transacciones comerciales internacionales, incluidos el comercio y la inversión, puede socavar el buen gobierno y el desarrollo económico, y distorsionar las condiciones competitivas internacionales ${ }^{43}$. Amén de disponer que se debe tipificar como delito el cohecho a los servidores públicos extranjeros, se establecen una serie de recomendaciones para fortalecer la lucha contra el cohecho. Es así que se dispuso de una guía de buenas prácticas para la aplicación de las medidas dispuestas en la Convención, entre otras, campañas para crear conciencia acerca de los perjuicios que tienen lugar y capacitaciones a los funcionarios públicos que vayan a prestar servicios al extranjero. También se dispone de una guía de buenas prácticas para las empresas, incluidas las multinacionales, en lo que se refiere, por ejemplo, a los regalos, dádivas o viajes de clientes. De la regulación citada se desprende que por medio de esta Convención ya se comienza a reconocer desde una perspectiva internacional la necesidad de prohibir los actos de corrupción que pudiesen afectar intereses económicos.

Respecto a la Convención sobre la corrupción de $2003^{44}$, se resalta ya en el preámbulo la importancia de enfrentarla, no sólo por los riesgos que para las instituciones y valores democráticos conlleva, sino también por los vínculos que se pueden dar con la criminalidad organizada y económica ${ }^{45}$. Asimismo, se destaca el carácter transnacional del fenómeno y el que, por ello, se requiera de medidas internacionales de cooperación para enfrentarlas. Cabe resaltar que las normas de la convención apuntan tanto al sector público como al privado. En este sentido, se trata de un instrumento internacional que trata la corrupción de forma integral ${ }^{46}$. Para tal efecto, se dispone de medidas preventivas y de represión; entre las primeras se destaca la necesidad de promover la participación de la sociedad y de que se disponga de la debida gestión de los asuntos públicos y los bienes públicos, la integridad, la transparencia y la obligación de rendir cuentas (art. 5). En relación a las medidas represivas se establecen disposiciones relativas a la penalización de comportamientos que atentan contra la administración pública, el orden socioeconómico y la administración de justicia. Entre los delitos que afectan a la administración pública se incluyen los delitos de malversación de caudales públicos y formas de desviación del

43 Rose (2015), pp. 65 y ss.; ZalaQuett (2011), pp. 181-182.

44 Ver la Convención en: https://www.unodc.org/documents/treaties/UNCAC/Publications/ Convention/04-56163_S.pdf. Antecedentes y estructura en RodríGuez y OsSANdón (2008), pp. 77-82.

45 Examen de la Convención en el Segundo Foro Internacional que tiene lugar en Santiago en 2010. Ver en: http://www.contraloria.cl/NewPortal2/portal2/ShowProperty/BEA\%20Repository/Portal/Actualidad/ Actividades/Foros/01-02122009.pdf.

46 Rose (2015), pp. 97 y ss. 
funcionario público, ya sea en su favor o de terceros. También se contempla el tráfico de influencias.

Se regula la corrupción en el sector privado, en el que se contempla el soborno sobre la base de entender que lo hay cuando, entre otras conductas, se hacen promesas, ofrecimientos o concesiones a una persona que dirija una entidad del sector privado o cumpla cualquier función en ella, de beneficios indebidos que redunden en su provecho o en el de otra persona, con el fin de que, faltando al deber inherente a sus funciones, actúe o se abstenga de actuar (art. 21). También se dispone la malversación de bienes en el sector privado (art. 22) y el blanqueo del producto del delito (art. 23). En el Capítulo V se aborda la recuperación de activos, disponiendo de medidas dirigidas a prevenir y detectar las transferencias del producto de delitos tipificados con arreglo a la presente Convención.

Como se desprende de esta descripción, la tendencia internacional ha llegado al punto de reconocer la necesidad de criminalizar la corrupción que se lleva a cabo exclusivamente entre particulares. Es decir, en el marco de la prevención de los efectos lesivos de la corrupción para intereses de naturaleza económica, se ha defendido que los actos de corrupción no necesariamente deben involucrar, en todo caso, a un funcionario público, sino que también tales intereses, principalmente vinculados a la protección de la competencia, pueden verse afectados por actos de corrupción que se efectúan completamente entre privados ${ }^{47}$.

Precisamente por lo expuesto es que los instrumentos internacionales -notoriamente en Europa- se han ido dirigiendo hacia la punición de la corrupción privada. Es así que, en la esfera de la Unión Europea, la Decisión Marco de 22 de julio de 2003 (2003/568/JAI) y con anterioridad la Acción Común de 22 de diciembre de 1998 y el Convenio del Consejo de Europa contra la corrupción

47 En nuestro país, actualmente se está discutiendo la criminalización de la corrupción entre particulares. En el boletín 10155-07, mensaje 500-363, se propone la creación de los siguientes tipos penales: "Art. 287 bis. El director, gerente, administrador o ejecutivo principal de una empresa o entidad que, por sí o a través de otra persona, solicitare o aceptare recibir un beneficio económico en interés o provecho propio o de un tercero, para favorecer, o por haber favorecido, con infracción de sus deberes u obligaciones, a otro en la contratación de bienes o servicios o en las relaciones comerciales, será sancionado con la pena de reclusión menor en su grado medio a máximo y multa del tanto al cuádruple del beneficio solicitado o aceptado.

Art. 287 ter. Con las mismas penas señaladas en el artículo anterior será sancionado el que, por sí o a través de otra persona, ofreciere o consintiere en dar o entregar a un director, gerente, administrador o ejecutivo principal de una empresa o entidad, o a quien estos señalen, un beneficio económico en interés o provecho propio o de un tercero, para que le favorezca, o por haber favorecido, a él o a un tercero frente a otros en la contratación de bienes o servicios o en las relaciones comerciales".

Si bien la relevancia de esta temática es innegable, excede los límites de este trabajo en razón de su extensión, constituyendo una arista a analizar en una investigación futura. 
de 27 de enero de 1999 impusieron a los Estados europeos la obligación de introducir dentro de sus normas internas el delito de corrupción en el sector privado. Justamente es en este contexto que España, por ejemplo, incorpora este delito en el artículo 286 bis del Código Penal. Al respecto debe tenerse presente que gran parte de los Estados europeos ya disponen de normas penales en esta materia. En todo caso, cabe advertir que en el pasado ya existía preocupación por aquellos comportamientos entre privados que podían considerarse reñidos con una competencia leal. Es así que en 1906 se aprueba en Gran Bretaña la ley sobre prevención de la corrupción y en Alemania se dicta en 1909 la ley contra la competencia desleal ${ }^{48}$.

La práctica de criminalizar tales conductas puede generar cierta perplejidad, ya que no puede negarse que, cuando se habla de corrupción, se presupone, tradicionalmente, la presencia de un representante de la administración públi$\mathrm{ca}^{49}$. Así lo ponen de manifiesto los instrumentos internacionales ya citados, que apuntan a la función pública, de acuerdo a los cuales la corrupción sería esencialmente el abuso de quienes detentan una función pública para obtener ganancias particulares, contraviniendo las normas propias de su cargo ${ }^{50}$, produciéndose, así, una suerte de privatización del acceso a la autoridad púbica ${ }^{51}$. Incluso el Diccionario de la Real Academia española establece como una de las acepciones de corrupción la siguiente: "En las organizaciones, especialmente en las públicas, práctica consistente en la utilización de las funciones y medios de aquéllas en provecho, económico o de otra índole, de sus gestores".

Sin embargo, si se examina la raíz de la expresión objeto de examen no se autoriza tal restricción. Corrupción viene del latín corruptio,-onis, que esencialmente significa alteración o vicio de algo o alguien en el que intervienen sujetos $^{52}$. Por tanto, nada impediría, desde una perspectiva etimológica, comprender la esfera privada. En este orden de cosas, cabe observar que en los últimos decenios ha habido una especial preocupación por entender que las modalidades de corrupción no serían sólo las relativas al ámbito público -expresadas en delitos como el cohecho, entre otros-, sino que se está prestando atención a la llamada corrupción privada, en cuanto se trataría de comportamientos irregulares en la esfera de los negocios, que alterarían la confianza en el mercado al afectar la

48 De la Cuesta Arzamendi y Blanco (2002), p. 258.

49 RodríGuez (2004), p. 352.

50 Como exponen Hodgson y JiAng (2007), p. 1044, comprender la corrupción sólo dentro de la función pública puede ser una mirada propia de los economistas.

51 FARALDO (2001), p. 69.

52 Mayor detalle en RodríGuez (2004), pp. 341 y ss. 
existencia de una competencia leal. Una tarea importante será, pues, precisar y delimitar el sentido y alcance de ambas formas de corrupción ${ }^{53}$.

Pero, además, en la actualidad esta materia adquiere particular relevancia frente a los cambios que ha impuesto la economía globalizada y la mayor intervención del mundo privado en la esfera de los negocios. En este sentido, el proceso de privatización de empresas estatales y la mayor incidencia en la vida del ciudadano común de las actividades que realizan las empresas privadas -no pocas de carácter transnacional-imponen ciertas pautas de comportamiento en la forma de hacer negocios (avance hacia una cultura empresarial). Es así que últimamente se ha observado una creciente necesidad de introducir componentes éticos en el mundo de los negocios (ética de los negocios). Precisamente por ello no se puede permanecer ajeno frente a quien se aprovecha indebidamente de ciertas ventajas. Lo anterior constituye un hecho reprobable, tanto desde un punto de vista de la ética de los negocios -pues se utiliza una ventaja que genera una posición de desequilibrio entre las partes- como desde una perspectiva de la ética en los negocios -dado el abuso de poder que se obtiene alterando la confianza de los intervinientes en el mercado- ${ }^{54}$.

Por lo reseñado es que se haría necesario analizar la introducción de disposiciones que se dirijan a aquellos comportamientos desleales o corruptos por parte de quienes intervienen en el tráfico económico ${ }^{55}$. Se está frente a una clase de actuaciones que afectan a la conciencia social y que rebasan los límites éticos con los que deben operar los agentes económicos. En definitiva, la pérdida de confianza que tales prácticas puedan producir en los otros agentes afectará el correcto funcionamiento del mercado, al alterar su transparencia.

\section{La corrupción en el ámbito de las transacciones comerciales internacionales como manifestación de esta preocupación. Especial referencia a la práctica estadounidense}

Como ha quedado en evidencia, el fenómeno de la corrupción se caracteriza por ser una forma de agresión que puede afectar bienes jurídicos muy variados. Por lo mismo, resultaría erróneo sostener que sólo bienes jurídicos vinculados al correcto desarrollo de la función pública podrían verse afectados por tal forma de conducta. Un claro ejemplo de lo anterior vendría dado por el hecho de que en nuestro país también se han incorporado figuras delictivas cuyo propósito es prevenir distorsiones en las reglas del mercado, específicamente en lo que

53 Así lo evidencia Gómez-Jara (2008), p. 226.

54 Al respecto, Seminara (1995), pp. 525-527.

55 Sobre este punto, BOlea (2013), pp. 10 y ss. 
respecta a ciertas condiciones de competencia que se consideran adecuadas para el desarrollo de la actividad económica.

Así, si nos remitimos al fundamento de la incriminación del cohecho a funcionario público extranjero en el ámbito de las transacciones económicas internacionales en nuestra legislación, tal vinculación queda en evidencia ${ }^{56}$. En este sentido, la doctrina penal nacional ha sostenido que a través de este tipo penal no se pretende proteger intereses vinculados al correcto desempeño de la función pública, en este caso del país extranjero respectivo, sino que un interés diverso. Para algunos lo que se protege es el "normal desarrollo de las relaciones económicas internacionales" ${ }^{57} \mathrm{O}$, en forma más específica, la "seguridad e igualdad jurídica para la sana competencia" ${ }^{58}$. En Chile se incorporó la figura del cohecho a funcionario público extranjero en 2002 -actual art. 251 bis y 251 ter del Código Penal-, a fin de dar cumplimiento a la obligación contraída al suscribir la Convención en comento ${ }^{59}$. En todo caso, este compromiso ya le

56 Lo anterior queda claro si se toma en cuenta lo dispuesto en el Preámbulo de la Convención de la OCDE ya mencionada: "Considerando que el cohecho es un fenómeno generalizado en las transacciones comerciales internacionales, incluidos el comercio y la inversión, que suscita graves preocupaciones morales y políticas, socava el buen gobierno y el desarrollo económico, y distorsiona las condiciones competitivas internacionales...".

57 Oliver (2003) pp. 42-44. En un sentido similar, Politoff et al. (2004), p. 508; RodríGuez y Ossandón (2008), pp. 355-357. La discusión en la época en que se introduce por primera vez este tipo penal se presentaba principalmente por la ubicación sistemática de este tipo penal, incluido en el mismo párrafo que el delito de cohecho a funcionario público nacional. Lo anterior habría llevado a tratar de definir si el bien jurídico era el mismo para ambos casos o no. Una de las modificaciones introducidas por la ley $N^{\circ} 20.341$ es incluir un nuevo párrafo (9 bis) con el objeto de evitar tal problema. Con todo, cierta doctrina es crítica a la nueva ubicación sistemática, así, por ejemplo, FABIÁN (2010), p. 78, de acuerdo con quien: "El cohecho activo previsto en el nuevo artículo 251 bis recae sobre servidores públicos pertenecientes a otros Estados o a Organizaciones internacionales de Derecho Público. Su contenido material, si desvalora, deberá vincularse a la tutela de tales administraciones exteriores -lo cual no parece tener sentido, pudiendo llegar a considerarse una injerencia en asuntos que competen a otros Estados- o, mucho más correctamente, del normal desarrollo de las relaciones económicas internacionales...".

58 SZCZARANSki (2011), p. 129.

59 Con más detalle, Oliver (2003), pp. 43 y ss. A través de la modificación introducida por ley No 19.826 se incorporan al Código Penal los artículos 250 bis A y 250 bis B. Como señala el mensaje presidencial (2001), a través de esta modificación se pretende cumplir las obligaciones contraídas en la Convención de la OCDE. Junto a esta modificación también se debía incorporar al sistema penal chileno la responsabilidad penal de las personas jurídicas. El 11 de julio de 2008 se ingresa indicación alterando sustancialmente esta regulación con el objeto de adecuar la legislación a las observaciones y sugerencias formuladas por la OCDE, efectuadas en el marco de la primera y segunda fase de evaluación del cumplimiento por Chile de la Convención señalada. Dentro de las observaciones más relevantes se cuentan, por ejemplo, a) la sugerencia de ampliar los verbos rectores para evitar vacíos de punibilidad, ya que el tipo penal chileno sólo contenía el "ofrecer" y no el "dar o prometer"; b) se observa que el tipo penal chileno limitaba la sanción a los casos de ofrecimiento de beneficios de naturaleza económica, en tanto que la Convención los extendía a cualquier ventaja 
era exigible al Estado chileno con la Convención Interamericana ${ }^{60}$. Si bien es cierto que este tipo penal ha tenido casi nula aplicación en la práctica ${ }^{61}$, es innegable la relevancia que tiene en la actualidad el análisis del fenómeno de la prohibición de la corrupción en el ámbito de las transacciones comerciales internacionales, sobre todo para un sector empresarial cada vez más globalizado y con mayor presencia en el extranjero.

Debido al escaso desarrollo de este tipo penal en nuestro país, nos centraremos en la experiencia comparada, atendiendo especialmente a aquella regulación que ha servido de referencia para nuestro legislador. El objeto de tal descripción es determinar en qué medida y con qué alcance la prohibición de actos de corrupción en el marco de las transacciones económicas internacionales incide en la protección de ciertas expectativas vinculadas con intereses económicos, principalmente relacionados a la participación en los negocios con el sector público en el extranjero.

Como señalamos con anterioridad, la figura del cohecho a funcionario público extranjero fue incorporada a nuestro ordenamiento jurídico-penal por la ley $\mathrm{N}^{\circ}$ 19.826, publicada en 30 de octubre de 2002. Los antecedentes que tiene a la vista el legislador son, en primer lugar, la Convención para combatir el cohecho a servidores públicos extranjeros en transacciones comerciales internacionales emanada de la OCDE, aprobada en marzo de 2001 y ratificada en abril del mismo año. A partir de tal ratificación nuestro país queda obligado a criminalizar tal hipótesis de soborno. Este instrumento da cuenta en forma

indebida; c) se solicita se explicite que la ventaja de la que se trate debía ser indebida; con el objeto de evitar problemas interpretativos; d) se indica que la expresión "transacciones comerciales internacionales" resultaba inadecuada, ya que dejaría fuera las transacciones de carácter civil" por lo que se solicita se elimine la expresión "comerciales"; e) se expresan diferencias en relación a la definición contenida en el artículo 250 bis B del Código Penal en relación a la contenida en el art. $1^{\circ}$ párrafo $4^{\circ}$ de la Convención, específicamente en lo relativo a la expresión "empresa de servicio público". Se sugiere la utilización de la expresión "empresa pública". Como se desprende de la redacción actual de los artículos 251 bis y 251 ter, nuestro legislador recoge cada una de estas observaciones. Éstas se encuentran disponibles en la web: OCDE (2004). "Chile: Phase 1. Review of Implementation of the Convention and 1997 Recommendation, Directorate for Financial and Enterprise Aff airs", http:// www.oecd.org/chile/44254056.pdf y OCDE (2007). "Chile: Phase 2. Report on the Application of the Convention on Combating Bribery of Foreign Public Officials in International Business Transactions and the 1997 Revised Recommendation on Combating Bribery in International Business Transactions", http://www.oecd.org/chile/39540391.pdf. La ley № 20.341, que agrega los artículos 251 bis y 251 ter, fue publicada el 22 de abril de 2009.

60 Rodríguez y OsSandón (2008), p. 356.

${ }^{61}$ A excepción de un reciente caso, en que se acuerda una suspensión condicional con la empresa Asfaltos Chilenos S.A., ya que no habrían adoptado mecanismos para la prevención de este delito y una intermediaria de la misma empresa habría sobornado a funcionarios públicos bolivianos. Ver, al respecto, http://papeldigital.info/lt/2015/12/21/01/paginas/022.pdf. 
evidente de que el fenómeno de la corrupción ya no es sólo un problema local, sino que ha adquirido dimensiones transnacionales que son dignas de preocupación ${ }^{62}$. Uno de los fenómenos que ha adquirido mayor relevancia es, sin duda alguna, el de la corrupción en el ámbito de las transacciones comerciales internacionales y, especialmente, el soborno a funcionarios públicos extranjeros en el marco de tales relaciones económicas.

Sin embargo, para comprender a cabalidad las razones que justificarían su criminalización y el alcance de esta prohibición, es necesario considerar uno de los mecanismos que ha tenido mayor influencia, como lo es la Foreign Corrupt Practices Act norteamericana (en adelante FCPA) ${ }^{63}$. De acuerdo a lo sostenido por Crites, el origen de este instrumento se remonta a un período en que las circunstancias globales y económicas no difieren realmente de lo que hemos vivido en los últimos tiempos ${ }^{64}$. Uno de los principales factores que explican el surgimiento de tal normativa fueron ciertos escándalos protagonizados por grupos empresariales. En este ámbito, aproximadamente 400 compañías

62 Al respecto, ver BeNITO (2012), pp. 32-33. De acuerdo a esta autora, a la "transnacionalización de la corrupción han contribuido, sin duda, algunos de los elementos caracterizadores de la era globalizadora, que se han unido a factores clásicos que tradicionalmente se han apuntado como favorecedores de las prácticas corruptas: la insuficiente tradición democrática, la amplia discrecionalidad de los funcionarios públicos, los complejos procedimientos administrativos, los procesos de privatización, la tolerancia social hacia las mismas, etc." (cursiva en original).

63 Es relevante tener en consideración que la criminalización de tal conducta en Estados Unidos es lo que gatilla que diversos organismos internacionales adopten la decisión de incluirla dentro de sus respectivas directrices para la lucha contra la corrupción. Como explica Benito Sánchez, las empresas multinacionales estadounidenses, al verse en una situación de desventaja respecto al resto de sus competidores internacionales, a los cuales no se les dirigía tal clase de prohibición, solicitan a sus respectivas autoridades que presionen a tales organismos internacionales para que el resto de los países incorporen tal prohibición. Con el objeto de describir y analizar el contexto internacional de la prohibición del cohecho a funcionario público extranjero nos centraremos en la realidad estadounidense debido a que es el ámbito donde ha habido mayor desarrollo jurisprudencial de este ilícito, además de que, como ya se indicó, es en este país donde se criminaliza por primera vez tal conducta. Con todo, un análisis acabado de este problema no puede prescindir de la consideración de los esfuerzos de la OCDE por homogeneizar las diversas regulaciones nacionales en aras de una persecución efectiva de este ilícito. Tal análisis no puede hacerse acá debido a la extensión del estudio. Dado a que se ha priorizado describir y analizar supuestos de hecho que han resultado problemáticos en el ámbito de la corrupción trasnacional, ha resultado más adecuado, para los fines del artículo, recurrir a la práctica estadounidense. Por último, no puede desconocerse la importante influencia que ha tenido la OCDE para la evolución de la FCPA. Véase Benito (2012), p. 56. Al respecto, ver Strauss (2013), pp. 247 y ss. También, aunque para el Reino Unido, Rose (2015), pp. 59 y ss. Resulta relevante analizar, al día de hoy, tal práctica, ya que como señala SHINGLER (2013), p. 537, a partir del año 2004, en Estados Unidos, luego del caso United States v. Kay, surge un verdadero reforzamiento de las pretensiones de cumplimiento de este instrumento. Ver también al respecto WeIss (2009), pp. 472 y ss.

64 CRITES (2012), p. 1050, refiriéndose tanto a período de crisis económica como de fuerte desconfianza de ciertas instituciones tanto públicas como privadas. Ver también, al respecto, BeNITO (2012), pp. 54 y ss. 
norteamericanas admiten que habían pagado cerca de 300 millones de dólares en concepto de sobornos a funcionarios públicos extranjeros. La razón por la cual se reacciona frente a tal hecho es que se empieza a poner en entredicho la confianza en la integridad del sistema del libre mercado ${ }^{65}$.

Con el objeto de prevenir tal situación, la normativa analizada establece dos clases de medidas diversas. Por un lado, prohíbe el soborno a oficiales públicos extranjeros y, por el otro, exige un alto estándar para el registro contable de las operaciones comerciales desarrolladas en el extranjero ${ }^{66}$. De acuerdo a lo sostenido por Benito Sánchez ${ }^{67}$, ciertos aspectos de esta normativa fueron especialmente influyentes en los instrumentos internacionales que prohíben el cohecho a funcionario público extranjero. Por tal motivo abordaremos brevemente su contenido.

Debido a que lo que interesa es determinar el margen de conductas que son consideradas como actos de corrupción en el ámbito de las transacciones económicas internacionales, atenderemos únicamente a la descripción de las principales conductas delictivas reguladas en la FCPA.

Así, se prohíbe a los respectivos destinatarios ${ }^{68}$ utilizar "el correo o cualquier medio o instrumento de comercio interestatal en forma corrupta a fin de promover una oferta, un pago, una promesa de pago o autorización del pago de cualquier suma, oferta, regalo, promesa de dar o autorización de dar cualquier cosa de valor" ${ }^{\prime \prime 9}$ a un funcionario público extranjero, a cualquier partido político extranjero o funcionario de ese partido o a cualquier candidato a un cargo político extranjero o, incluso, a cualquier persona, si se lleva a cabo esta conducta a sabiendas de que todo o parte de estos dineros se destinará -bajo cualquiera de las modalidades permitidas por este instrumento- a cualquiera de los sujetos anteriormente señalados.

65 Zyla (2011), p.13. También, Benito (2012), p. 55: "El objetivo de esta ley fue acabar con determinadas prácticas indignas que venían aconteciendo, de manera más o menos habitual, en el comercio internacional y que lesionaban la libre competencia que debe presidir las relaciones económicas transnacionales, pues con dichas prácticas se expulsa del mercado a los competidores de buena fe". En relación a la evolución de este instrumento, ver WESTBROOK (2011), pp. 510 y ss.

66 CRITES (2012), p. 1053; ZYLA (2011), p. 13: “Companies must mantain a system of internal accounting controls, such a periodic audits of financial statements, that will help auditors and compliance officers catch suspicious payments". Ver al respecto Loughman y Sibery (2011), p. 464.

67 BeNITO (2012), pp. 58 y ss.

68 FCPA, Título 15, capítulo 2B, Sección 78m, a). Ver al respecto Loughman y Sibery (2011), p. 379. También, KOEHLER (2010), pp. 389-390.

69 FCPA, Título 15, capítulo 2B, Sección 78dd-1, a). Se citará la versión en castellano disponible en web del Departamento de Justicia de EE.UU.: http://www.justice.gov/sites/default/files/criminal-fraud/ legacy/2012/11/14/fcpa-spanish.pdf. 
Con todo, tales ofrecimientos a las personas indicadas sólo son prohibidos si se efectúan con determinados propósitos, a saber: el de influir en cualquier acto o decisión de dicho funcionario; inducirlos a que realicen u omitan algún acto en infracción de su deber legítimo, obtener alguna ventaja indebida, o, por último, inducir a dichos sujetos a que ejerzan conductas de tráfico de influencias en los respectivos gobiernos extranjeros o instrumentos del mismo para afectar un acto o decisión de dicho gobierno o instrumento, siempre y cuando se efectúen con el fin de ayudar a dicho emisor a obtener o retener algún negocio para alguna persona o con ella, o para encaminar algún negocio hacia alguna persona.

En términos sencillos, se prohíbe el soborno a un amplio grupo de personas, que tienen en común el hecho de que actúan en representación de intereses estatales o que pueden influir en las decisiones del mismo, como en los casos de los representantes de partidos políticos o candidatos a cargos públicos. No resulta relevante el hecho de que se actúe a través de intermediarios, para que, en forma incompatible a los intereses que representan, otorguen ciertas ventajas indebidas en relación a la mantención u obtención de un negocio en que el Estado sea la respectiva contraparte.

En relación a la delimitación de esta figura delictiva, se ha sostenido por cierta doctrina que una de las principales características de esta regulación es su evidente ambigüedad ${ }^{70}$, lo que plantea una serie de dificultades interpretativas, pese a los intentos de la FCPA por definir algunos de estos términos. Al respecto se deben tener en cuenta los siguientes aspectos centrales:

a) La FCPA define expresamente lo que se deberá entender por funcionario público extranjero: "cualquier funcionario o empleado de un gobierno extranjero o de algún departamento, dependencia o instrumento del mismo, o de una organización internacional pública, o de alguna persona que actúe a título oficial para dicho gobierno, departamento, dependencia o instrumento, o en nombre del mismo, o para dicha organización internacional pública o en nombre de la misma"71.

Desde una perspectiva político-criminal se debe señalar que la amplitud del concepto es adecuada. Para la protección de la competencia de los actos de corrupción resulta más eficiente contemplar una hipótesis amplia de eventuales

70 Expresamente al respecto, SHINGleR (2013), p. 541, de acuerdo con quien la mayor parte del lenguaje utilizado por este instrumento es sumamente amplio y ciertos elementos son particularmente controversiales.

71 FCPA, Título 15, capítulo 2B, Sección 78dd-1, f), 1), A), o dependiendo del destinatario de la prohibición, Sección 78dd-2, h), 2), A) y Sección 78dd-3, f), 2), A). Debido a que el contenido de tales definiciones es prácticamente el mismo en las tres secciones, en adelante se optará por citar sólo una de éstas a modo de ejemplo. 
sujetos destinatarios del soborno. Lo relevante es constatar que los mismos representan al Estado, u otros organismos internacionales, y que, a través de un abuso de su poder decisorio ${ }^{72}$, es decir, actuando en forma incompatible a los deberes de su cargo, puedan alterar las reglas del juego en el ámbito de las transacciones comerciales en las que toman parte, ya sea en forma directa o indirecta, por ejemplo, ejerciendo una influencia indebida en otros funcionarios que tengan tal poder decisorio. Por lo mismo se comprende que se incluya dentro de la prohibición del soborno no solamente a tales funcionarios, sino que también a partidos políticos extranjeros, funcionarios de tales partidos o candidatos a un cargo político. Es evidente que, por los vínculos que pueden tener los mismos con los funcionarios de los gobiernos de turno u otras autoridades políticas, podrían incidir en que terceros obtuvieran ventajas comparativas indebidas en la obtención o la mantención de un negocio.

Pero, además, tal decisión es coherente si se piensa que lo que se pretende es proteger la competencia de determinada forma de agresión, es decir, la corrupción. Para que estemos frente a un acto de corrupción es fundamental que se pretenda influir en un sujeto que deba actuar en representación de los intereses de otro, ya sea un Estado extranjero o una organización internacional pública, con el propósito de que abuse de tal poder de representación, específicamente su poder decisorio, priorizando intereses diversos e incompatibles con los de su representado ${ }^{73}$.

b) Como señala Benito Sánchez, se exige un "vinculo de territorialidad" entre el país del funcionario que recibe el soborno y los Estados Unidos. Por tal razón este instrumento requiere que se cumplan ciertos requisitos como la utilización del correo u otros medios de comercio interestatal para realizar el ofrecimiento del soborno o la entrega de la ventaja indebida ${ }^{74}$.

c) De acuerdo a Loughman y Sibery, "cualquier cosa de valor" ha sido interpretado en forma amplia, pudiéndose incluir en tal categoría el dinero en efectivo, regalos "espléndidos" o "dadivosos" o gastos de entretenimiento, contribuciones impropias o ilícitas a campañas políticas, becas escolares, viajes familiares, pagos excesivos por la prestación de servicios o la asignación de precios bajo el mercado por activos ${ }^{75}$. Pacini sostiene que en la actualidad se considera que satisfacen este requisito casos como el de otorgar empleos

\footnotetext{
72 Adherimos así a lo sostenido por KINDHäUSER (2007), pp. 6-7, en relación a los elementos de la corrupción.

73 Al respecto, en detalle KINDHÄUSER (2007), pp. 5-6.

74 Benito SÁnchez (2012), p. 60, por lo mismo, de acuerdo a la autora: "si el comportamiento corrupto se lleva a cabo enteramente en el extranjero no podría aplicarse la FCPA aunque estuviese implicado un agente estadounidense".

75 Loughman y Sibery (2011), p. 521.
} 
a funcionarios públicos en calidad de consultores, los pagos por concepto de gastos de viaje, la concesión de préstamos con tasas de interés especialmente favorables, salidas a jugar golf, la entrega de equipamiento deportivo, las becas o descuentos escolares, etcétera ${ }^{76}$.

d) Uno de los elementos más relevantes de esta figura delictiva es la exigencia de un vínculo comercial respectivo (business nexus requirement). De acuerdo a lo sostenido por Pacini, se admite acá una interpretación amplia de este requisito. Así, por ejemplo, el término "negocios" no ha sido limitado exclusivamente a los contratos que se celebren con gobiernos extranjeros, sino más bien se ha incluido cualquier actividad comercial ${ }^{77}$. Destaca el caso U.S. v. Kay, donde la cuestión que se plantea, y se debe resolver, es si el pago a empleados públicos haitianos para la rebaja de impuestos y aranceles locales satisfacía o no el requisito del vínculo comercial. Al respecto, la corte competente (Fifth Circuit Court of Appeals) considera que tales pagos, si bien podrían otorgar una ventaja competitiva injusta y facilitarían que los otorgantes de tal pago obtengan o retengan negocios, no necesariamente debieran ser considerados automáticamente como pagos vinculados con la obtención o mantención de un negocio. Como lo expresa el tribunal, de la historia legislativa se desprende que el legislador pretendería extender la responsabilidad a las situaciones donde tales pagos, entendidos como una forma de soborno, pudieran mejorar las oportunidades para obtener o mantener el negocio, aparte de los casos en que derechamente permitieran su obtención o mantenimiento ${ }^{78}$.

e) Como se describió más arriba, este instrumento no sólo sanciona el soborno directo a funcionarios públicos extranjeros, sino también el pago a intermediarios para que lo hagan ${ }^{79}$. De acuerdo a lo señalado por Pacini, la

76 PaCINI (2012), p. 563. De acuerdo al autor se han incluido aquí, incluso, planes de formación a oficiales chinos, cuando tales programas no estaban específicamente relacionados con los negocios o productos de la empresa que otorgó el beneficio.

77 PACINI (2012), p. 568.

78 PaCINI (2012), p. 568. Como describe este autor, en Estados Unidos, la Securities and Exchange Commission (en adelante SEC) y el Department of Justice (en adelante DOJ) han continuado interpretando este requisito en forma tal que incluirían también los pagos efectuados con el propósito de influir en las decisiones gubernamentales que tengan un impacto positivo en los negocios de los acusados. En el fondo, se sancionaría tales conductas en la medida en que fueran idóneas para generar ventajas competitivas indebidas respecto a otros eventuales competidores.

79 En relación a las críticas que se han efectuado a la redacción del artículo 251 bis, destaca lo señalado por FABIÁN (2010), pp. 80-81, de acuerdo con el cual las autoridades chilenas habrían decidido solucionar el problema de la autoría mediante persona interpuesta a través de las reglas generales sobre autoría y participación, no siguiendo así la técnica utilizada por la OCDE en su Convención, la que castiga tanto "cuando el particular actúe personalmente como cuando lo haga mediante interme- 
acreditación del conocimiento del pago al funcionario por lo general no es un problema en los casos de soborno directo, pero sí sería un punto muy controvertido cuando se trata de la utilización de intermediarios. La FCPA prohíbe los pagos a cualquier persona a sabiendas de que todo o parte del mismo, o un artículo de valor, se ofrecerá, entregará o prometerá, directa o indirectamente, a cualquiera de los sujetos ya mencionado, y con los propósitos ya descritos. En este orden de cosas, la FCPA otorga una serie de criterios para determinar cuándo se entiende que un sujeto actúa a sabiendas:

A) Se considera que una persona "actúa a sabiendas" con respecto a una conducta, una circunstancia o un resultado si: esa persona es consciente de que se dedica a dicha conducta, que dicha circunstancia existe, o que es sustancialmente cierto que dicho resultado vaya a ocurrir; o esa persona cree firmemente que dicha circunstancia existe o que es sustancialmente cierto que dicho resultado va a ocurrir.

B) Cuando se requiere el conocimiento de la existencia de una circunstancia particular para un delito, se establece dicho conocimiento si una persona es consciente de que existe una gran probabilidad de la existencia de dicha circunstancia, a no ser que la persona crea realmente que dicha circunstancia no existe ${ }^{80}$.

Siguiendo con la descripción que hace Pacini de este instrumento, se puede decir que tal definición de conocimiento es bastante más amplia que la exigencia de un conocimiento actual. En la actualidad, y como lo expone este autor, la Securities and Exchange Commission (SEC) y el Departament of Justice (DOJ) estadounidense sostendrían que este requisito se cumpliría incluso para los casos en que los acusados no hayan cumplido con el debido cuidado frente a determinadas señales de alerta relativas a que un tercero pueda efectuar tales pagos indebidos. Con todo, tal estándar no sería recogido por los tribunales, para los cuales no bastaría la mera negligencia para satisfacer este requisito ${ }^{81}$.

f) Además, este instrumento exige que el pago u ofrecimiento deba efectuarse en forma corrupta, lo que no ha sido fácil de definir. Ahondaremos especialmente en este aspecto, debido a lo relevante que resulta para la delimitación conceptual de la corrupción en este ámbito. Para esto, no sólo atenderemos a lo señalado por la doctrina especializada, sino que también consideraremos los criterios que otorgan las mismas FCPA para la delimitación de lo que debiera

diarios". Señala que la opción chilena presentaría algunos inconvenientes vinculados a la regulación interna de la inducción y la autoría mediata.

80 FCPA, Título 15, capítulo 2B, Sección 78dd-1, f), 2).

81 PACINI (2012), p. 567. 
entenderse por acto de corrupción. En este sentido, se deberán considerar los criterios negativos que contempla este instrumento a través de una excepción y dos clases de defensa.

De acuerdo a cierta doctrina, se ha interpretado como referido a la "contrariedad al Derecho del país al cual pertenece el funcionario público sobornado" ${ }^{\prime 22}$. Se ha sostenido también que el elemento "corruptamente" puede significar una variedad de cosas, entre las que se incluyen el pretender obtener algo quid pro $q u o$, intentar influenciar a otro en forma impropia, actuar en contra de la ley o actuar en forma oculta o subrepticia, etcétera ${ }^{83}$.

Para resolver este problema es necesario, según nuestra opinión, tomar en consideración el lugar o papel que juega este elemento dentro de la conducta delictiva y la naturaleza que se le ha asignado al mismo. Pacini señala que para la definición de este elemento se puede recurrir a la historia legislativa de las FCPA, de acuerdo a la cual pareciera que la mejor forma de entenderlo sería como un elemento del ánimo del agente o como un propósito determinado.

Así las cosas, la palabra corruptamente serviría para indicar que el ofrecimiento, el pago, la promesa o regalo debe efectuarse para inducir al receptor a infringir deberes propios de su cargo para beneficiar, en un sentido muy amplio, a quien efectúa el pago. En este sentido, se señala expresamente que la palabra corruptly implica un motivo o propósito maligno o intento de influenciar en forma negativa a tal receptor ${ }^{84}$ para alcanzar un objetivo ilícito o incluso un fin lícito pero a través de medios ilícitos. Un buen ejemplo para entender el papel que se le asigna a este elemento está dado por el análisis que hace Green del delito de cohecho, en la medida en que señala que lo único que distinguiría "el soborno de un regalo legítimo es un elemento mental de intención muy difícil de probar (o, de modo aún más oscuro, un elemento de 'corrupción')"85.

Con todo, si bien es cierto el elemento subjetivo es imprescindible a la hora de determinar si se está frente a un acto de corrupción, como es propio de la atribución de responsabilidad penal, se debe atender en primer lugar a criterios objetivos para la determinación de si la conducta en particular puede ser

\footnotetext{
82 BeNITO (2012), p. 60.

83 Loughman y Sibery (2011), p. 545. Ver también, Pacini (2012), p. 549.

84 PACINI (2012), p. 562. En este orden de cosas, el autor mencionado da cuenta de la interpretación que se le ha otorgado a este término en algunos casos emblemáticos como, por ejemplo, United States $v$. Liebo, en donde se instruye al jurado acerca del significado de este término en forma tal que se indica que el ofrecimiento, promesa de pago, pago, o la autorización para el pago debe estar dirigido, entre otros casos, a que el receptor abuse de su oficio u posición oficial, lo que se lleva a cabo en forma corrupta si se hace en forma intencional y voluntaria y con un "mal propósito", el de alcanzar ya sea un fin ilícito o un fin lícito, pero a través de medios ilícitos.
}

85 Green (2013), p. 257. 
considerada como contraria a la prohibición respectiva. Para tales efectos, el termino corrupción no puede ser interpretado únicamente como una intención, sin antes definir qué se entenderá por "corruptamente" en el ámbito objetivo. De acuerdo a lo que hemos venido sosteniendo, este término está vinculado necesariamente a la desnaturalización de determinada función de representación de intereses de otro a través del abuso de un poder decisorio. Por lo mismo, y como se analizará más adelante, para la delimitación del comportamiento prohibido se debe atender a si el soborno está dirigido o no a que el funcionario respectivo abuse de su poder decisorio, es decir, que actúe en forma incompatible con los intereses que debe representar, o para que un intermediario u otro, como un funcionario de un partido político, incidan en que éstos actúen de una determinada forma. Tal punto de partida será fundamental para entender las posibilidades de defensa frente a la imputación de un acto de corrupción.

g) Como se señaló más arriba, la delimitación de las conductas que son punibles de acuerdo a este instrumento sólo se puede llevar a cabo una vez se consideren ciertas circunstancias que, bajo la forma de una excepción y dos defensas, imposibilitarían la sanción.

La excepción consiste en excluir de la prohibición todos los pagos a tales funcionarios cuyo propósito sea facilitar, agilizar o conseguir la realización de un acto gubernamental de rutina por parte de estos mismos (facilitation payments) ${ }^{86}$.

De acuerdo a Pacini, el objeto de tal excepción es reconocer el hecho de que, en ciertos países, el pago de pequeñas cantidades para facilitar los negocios (grease payments) debe ser considerado como parte de los "costos de hacer negocios ${ }^{\prime 87}$, o, como sostiene Shingler, esta excepción permitiría a los empresarios estadounidenses operar en el extranjero pagando pequeñas cantidades para posibilitar las operaciones diarias de su negocio en los casos en que las mismas podrían no ocurrir sin estos pagos ${ }^{88}$.

Como resulta obvio, una de las principales preocupaciones en este sentido es otorgar criterios para diferenciar pagos prohibidos de aquellos que deben entenderse como la excepción, ya que, si se toma en consideración el carácter amplio con el cual se ha interpretado el requisito de la "vinculación comercial",

\footnotetext{
86 FCPA, Título 15, capítulo 2B, Sección 78dd-1, b): Excepción a la acción gubernamental de rutina Las subsecciones a) y i) de esta sección no se aplicarán a ningún pago de facilitación ni agilización a un funcionario extranjero, partido político o autoridad del partido cuyo propósito es agilizar o asegurar el desempeño de una acción gubernamental de rutina por parte de un funcionario extranjero, partido político o autoridad del partido.

87 PACINI (2012), p. 569. De acuerdo a este autor, esta excepción fue creada en 1988, debido al reclamo de ciertas empresas porque los negocios internacionales se verían mermados en forma sustancial sin este tipo de pagos.

88 SHINGLER (2013), p. 544.
} 
estos pagos podrían perfectamente considerarse como aquellos que facilitan la obtención o mantenimiento de un negocio. Strauss clarifica que tal excepción tiene por objeto facilitar la ejecución de ciertas tareas gubernamentales ${ }^{89}$, consideradas como "de rutina" y que se encuentran ejemplificadas en el mismo instrumento ${ }^{90}$. De acuerdo a este autor, nunca podrán considerarse como actos de rutina aquellos en que el oficial extranjero ejerza facultades discrecionales propias de su cargo ${ }^{91}$. Al respecto la FCPA al menos otorga un criterio negativo relativo a los casos que no podrían considerarse, bajo ningún caso, como actos de rutina:

La expresión "acción gubernamental de rutina" no incluye ninguna decisión que tome un funcionario extranjero de adjudicar nuevos negocios a una parte en particular, o en qué condiciones, o de seguir realizando negocios con dicha parte, ni cualquier medida que tome un funcionario extranjero que participe en el proceso de toma de decisiones para instar a que se tome una decisión de adjudicar nuevos negocios a una parte en particular o de seguir realizando negocios con la misma ${ }^{92}$.

Como señala Pacini, la historia legislativa proveería de cuatro criterios para resolver este problema, vinculados, principalmente, a la constatación del fin que perseguiría el pago respectivo. Así, pertenecerían a la categoría de pagos ilícitos: a) los efectuados con el propósito de alterar el proceso de toma de decisión discrecional con el objeto de aumentar o mejorar los negocios del oferente; b) los inusualmente altos o elevados en relación a la gestión desplegada por el funcionario; c) aquellos que directamente puedan afectar la "competencia en los contratos" con el gobierno; d) los otorgados a cambio de servicios por los cuales el sobornado no tenga derecho ${ }^{93}$. De acuerdo a lo sostenido por Strauss,

\footnotetext{
89 Strauss (2013), p. 241.

90 Al respecto, dispone la FCPA en el Título 15, capítulo 2B, Sección 78dd-1, f), 3), A): El término "acción gubernamental de rutina" significa solamente una acción que de ordinario y por lo común la desempeña un funcionario extranjero para:

i) obtener permisos, licencias u otros documentos oficiales para que una persona pueda realizar actividades comerciales en un país extranjero;

ii) tramitar documentos gubernamentales, como visas y órdenes de trabajo;

iii) proporcionar protección policial, recolección y entrega de correspondencia o programación de inspecciones relacionadas con el desempeño contractual o inspecciones relacionadas con el tránsito de bienes a través del país;

iv) proporcionar servicios de teléfono, energía y agua; servicios de carga y descarga; protección de productos o artículos perecederos contra el deterioro, o

v) realizar acciones de índole similar.

91 El término utilizado por el autor es official discretion, Strauss (2013), p. 241.

92 FCPA, Título 15, capítulo 2B, Sección 78dd-1, f), 3), B).

93 PACINI (2012), p. 569.
} 
debido a lo vago que resultan estos criterios y la rigurosa persecución en Estados Unidos, los acusados por este delito son reacios a alegar esta excepción. A lo anterior se le sumaría el hecho de que por lo general tales pagos estarían, a su vez, prohibidos y muchas empresas estarían prohibiéndolos expresamente para evitar correr el riesgo de malos entendidos, los que se darían, la mayoría de las veces, debido a las exigencias relativas al control contable propias de la FPCA y lo vago que resultarían tales reportes en estos casos. Todo lo anterior ha derivado en que parte de la doctrina dude acerca de la conveniencia de seguir considerándolos como una excepción a los casos de pagos ilícitos ${ }^{94}$.

Así, por ejemplo, y ampliando el rango de la regulación internacional de la prohibición de la corrupción en el ámbito de las transacciones comerciales internacionales, se debe señalar que la Bribery Act de 2010 del Reino Unido no contempla tal excepción ${ }^{95}$ y que incluso la misma OCDE revierte el tratamiento que hacía de esta situación, ya que en 1997 la permitía expresamente. Como señala Strauss, este organismo sostiene, doce años después, que tales pagos eran corrosivos para el Estado de Derecho y para el desarrollo sustentable, especialmente de los países en desarrollo. Una lucha efectiva y "vigorosa" contra la corrupción suponía, entonces, evitar la permisión de tales pagos. Por lo mismo, la OCDE instruye a sus miembros a tomar medidas periódicas y revisar sus políticas relativas a tales pagos con el objeto de poder combatir efectivamente tal fenómeno. Asimismo, se incentiva a que los países miembros motiven a sus empresas para que prohíban o desincentiven estos pagos a través de sus procesos de control internos, programas de cumplimiento o códigos de ética o conducta, debido a que se reconoce que estos pagos están prohibidos en la mayoría de los países ${ }^{96}$.

Al respecto, podemos sostener que si bien es cierto que conviene evitar incluir los pagos para facilitar trámites como una excepción genérica, ya que podría servir para defraudar la prohibición de los actos de corrupción, sí podrían considerarse como excepción aquellos pagos efectuados con el solo propósito de posibilitar que un funcionario público lleve a cabo las labores propias de su cargo en aquellos casos en que si no se realiza tal pago, la labor simplemente no podría ejecutarse por razones no imputables al sujeto que paga.

Piénsese, por ejemplo, en un empresario extranjero que desea participar en el proceso de licitación para la adjudicación de un contrato con el Estado respectivo de cierta obra. Dentro del proceso requiere la certificación de haber

94 Strauss (2013), p. 258.

95 Ver al respecto, Richard (2014), p. 427; Loughman y Sibery (2011), p. 876.

96 Strauss (2013), p. 248. 
sido acompañados en el tiempo oportuno los antecedentes necesarios. Sin embargo, el funcionario público competente no cuenta en ese momento por falta de fondos con la implementación para cursar tal certificado, el cual constituye un requisito esencial para poder seguir participando en el resto del proceso de licitación. Frente a dicha situación, el empresario le otorga una suma de dinero con el propósito de solucionar el problema, para así obtener en breve la certificación respectiva.

Se puede suponer que tal pago no está autorizado por el ordenamiento jurídico respectivo. Pero en tales casos no podría sostenerse que se trate de un verdadero acto de corrupción si efectivamente se realizan con el solo propósito de posibilitar que el funcionario realice las labores propias de su cargo, sin que lo anterior genere una ventaja indebida en relación al resto de los interesados en el negocio. Esto, en la medida que no posibilita la desnaturalización de la pauta ideal de conducta que debiera seguir el funcionario público respectivo. A tal conclusión podría haberse arribado igualmente sin existir tal excepción, debido a que quien paga con tal propósito no lo hace "corruptamente", como lo exige la FCPA.

El instrumento analizado dota a los acusados de dos eventuales defensas que pueden hacer valer ante los tribunales a modo de respuesta frente a la imputación ${ }^{97}$. El foco de éstas, según lo señalado por Strauss, es dar cuenta de una serie de hechos que puedan incidir en que los pagos efectuados (o la respectiva promesa) debieran ser considerados como legítimos ${ }^{98}$. La primera de estas posibilidades de defensa es sostener que el pago efectuado al funcionario público extranjero fue lícito en el país respectivo (legality of the payment), la segunda consiste en alegar que el gasto fue efectuado de buena fe (bona fide expenditure).

En relación a la primera de éstas, si el pago está autorizado en el país que representa el respectivo funcionario, la conducta no podría ser considerada un delito $^{99}$. Esta posibilidad no siempre fue pacífica en el marco de la evolución de este instrumento, ya que la legalidad del pago no necesariamente debe deter-

97 Una buena forma de identificar la diferencia con la excepción ya descrita (pagos por actos de rutina) es considerar lo señalado por PACINI (2012), p. 572: "Las defensas afirmativas son sólo eso: no son excepciones. La parte acusada por la violación de la FCPA debe probar que los pagos satisfacen la defensa afirmativa".

98 Strauss (2013), p. 243.

99 Incluso este instrumento lo contempla de la siguiente manera: "El pago, regalo, ofrecimiento o promesa de cualquier cosa de valor que se haya hecho sea legítimo en virtud de las leyes y reglamentos escritos del país del funcionario extranjero, partido político extranjero o funcionario de ese partido o candidato". Ver, desde una perspectiva histórica, NiETO (2003), pp. 12-13, donde describe cómo en el gobierno de Reagan se modifica la FCPA con un objetivo indudablemente limitador. Por un lado, "el 
minarse de acuerdo a estándares distintos de los propios de los Estados Unidos. Como explica Nieto, "en su versión original la FCPA pretendía que las empresas multinacionales americanas actuasen en el extranjero con los mismos patrones morales que lo hacían en el interior, y exportaran de este modo la moral de los negocios norteamericana...". ${ }^{100}$ Con todo, luego de la reforma respectiva efectuada en 1988 cambia tal punto de partida y se determina la legalidad del pago en razón de lo permitido en el país en el que se efectúa.

Eso sí, y como se desprende de este instrumento, la defensa sólo podría ser esgrimida en caso de que el pago respectivo se efectúe de acuerdo a la normativa escrita del país donde se efectúan las relaciones comerciales; por ende, no puede ser alegada en caso de que el pago se haya efectuado de acuerdo a las costumbres o las prácticas asentadas del mismo ${ }^{101}$.

Con el objeto de comprender el alcance de esta defensa resulta útil considerar lo decidido en el caso United States v. Kozeny ${ }^{102}$, en el cual se debió resolver el siguiente supuesto de hecho: Kozeny efectuó una serie de pagos a funcionarios públicos de Azerbaiyán con el objeto de incentivar el proceso de privatización de la empresa nacional de petróleo y así poder participar de tal proceso. La defensa del acusado argumenta que el pago efectuado fue legal bajo los parámetros de la ley local, debido a que en este país se excluiría la responsabilidad en tales clases de delitos si quien había efectuado el pago denunciaba el hecho ante el presidente de Azerbaiyán. De acuerdo al Código Penal respectivo, los sujetos que hayan otorgado un soborno estarán exentos de responsabilidad penal si se trataren de víctimas de extorsión por parte de quien les solicita el pago o para los casos en que, después de haber sobornado, reporten voluntariamente lo ocurrido. Para este caso el tribunal estadounidense resolvió que no podía excluirse la responsabilidad si efectivamente se había infringido el ordenamiento jurídico del país extranjero, pero no se había producido la persecución penal por aplicación de otras disposiciones jurídicas.

Este punto es central porque demuestra que el foco está colocado en la licitud del pago desde la perspectiva de los intereses protegidos por esta normativa. Esto es, el de las condiciones adecuadas para competir en el ámbito de las transacciones económicas internacionales. Si bien es cierto, que el país en

tipo subjetivo se reduce a los supuestos claramente intencionales (...) y, de otro, se admiten más casos de pagos justificados", p. 13.

100 Nieto (2013), p. 13.

101 PACINI (2012), p. 571.

102 Información extraída de Strauss (2013), p. 243. El caso puede consultarse en la web: http:// www.justice.gov/sites/default/files/criminal-fraud/legacy/2012/06/01/2011-12-14-kozenyv-opinionsecond-circuit.pdf. 
cuestión decide no perseguir tales conductas, no lo hace por considerar que el pago es correcto o permitido, sino única y exclusivamente, como sostiene el tribunal, debido a que pretende generar incentivos para poder perseguir al funcionario público que acepta o solicita pagos no autorizados ${ }^{103}$.

Pero, además, esta defensa debe ser considerada como coherente en la medida en que la constatación de que se ha efectuado un pago en forma autorizada por el ordenamiento jurídico respectivo impide considerar el mismo como efectuado en forma corrupta, debido a la exigencia de que el mismo pago pueda servir como una razón para actuar en forma incompatible con los intereses que el funcionario debe representar. Por lo mismo, no puede ser considerado como un acto de corrupción un comportamiento dirigido a que el funcionario actúe de acuerdo con sus posibilidades legítimas de actuación.

Si bien es cierto que no se relaciona con la defensa analizada, el fallo en comento es sumamente importante en la medida en que establece que los casos de verdadera extorsión no pueden caber bajo la prohibición de la FCPA, justamente porque tales actos no pueden ser entendidos, a su vez, como actos de corrupción por parte del destinatario de la prohibición. Para tales efectos, el tribunal sostiene que es muy distinto acceder a pagar a un funcionario extranjero con el objeto de poder entrar a competir a un mercado o para obtener un contrato, que pagar para evitar, por ejemplo, que se dinamite una plataforma petrolífera, caso que debiera ser considerado como "verdadera extorsión"104. De acuerdo al razonamiento del tribunal, el motivo por el cual se podría sancionar en el primer caso, y no en el segundo, es que quien paga no podría sostener que no tuvo la intención de sobornar al funcionario ya que tomó una "decisión consciente" de pagarle. Como sostiene el tribunal en el primer ejemplo, quien paga "podría haber dado media vuelta y alejarse del lugar", lo que no sucede en el segundo caso. Como es obvio, quien actúa coaccionado actúa por tal motivo y no en forma corrupta.

Junto a la defensa anterior se incluye, también como defensa positiva, la denominada "bona fide expenditure defense", de acuerdo con la cual se puede responder por parte del acusado que los gastos efectuados -a título de regalo, ofrecimiento o promesa de cualquier cosa de valor- deben ser considerados como razonables y efectuados de buena fe con el objeto de promocionar, demostrar o explicar productos o servicios. También se incluirían dentro de esta defensa aquellos pagos efectuados de la misma manera, pero con el objeto de ejecutar o realizar un contrato con un gobierno extranjero u organismo de éste. Como explica Shingler, esta defensa plantea algunos problemas interpretativos

103 Shingler (2013), p. 244.

104 Strauss (2013), p. 244. 
relativos principalmente a la determinación de cuándo los gastos efectuados para generar relaciones comerciales o beneficios futuros se transforman derechamente en soborno ${ }^{105}$. Señala que el problema que se presenta para delimitar el contenido de esta defensa es que no podría ser considerado como una regla que especifique claramente, al menos en este caso, cuál sería la conducta permitida, sino que adoptaría más bien la naturaleza de un "estándar", el que simplemente establecería una guía general tanto para los órganos persecutores como para el eventualmente acusado por estos cargos, sin especificar en forma detallada qué es lo ordenado o lo prohibido. Debido al escaso pronunciamiento de los tribunales respecto a esta defensa, tampoco se habrían generado los precedentes suficientes como para dotarla de un contenido más preciso ${ }^{106}$.

Con todo, uno de los principales problemas que se ha presentado en la práctica, en relación con tal defensa, es que se podría utilizar para esconder pagos excesivos que efectivamente debieran ser considerados como soborno, bajo la categoría de pagos razonables para la promoción de un producto o negocio ${ }^{107}$. Al respecto, Pacini da cuenta que en el caso U.S v. Metcalf \& Eddy, Inc., el DOJ considera que los gastos efectuados en dos ocasiones consistentes en viajes en primera clase y en instalaciones hoteleras de lujo para un funcionario público egipcio y su familia no podían ser considerados como razonables ${ }^{108}$.

Para resolver tales problemas se debe atender, a nuestro juicio, a criterios similares a los utilizados con anterioridad. Si lo relevante es evitar que las reglas de la competencia se vean alteradas debido a actos de corrupción, un desarrollo adecuado de este último término serviría para delimitar en forma más precisa esta defensa. Para sostener que estamos frente a un acto de corrupción se requiere, en todo caso, que el pago o beneficio se efectúe para que el funcionario respectivo actúe en forma incompatible con los intereses de quienes representa. Lo anterior explica que ciertos gastos en los que haya incurrido

\footnotetext{
105 SHINGLeR (2013), p. 551. Para tales efectos considera que se puede atender a la opinión del DOJ, sobre todo porque este aspecto tampoco habría sido muy abordado por la jurisprudencia. Con todo, estas opiniones que emite el DOJ sólo se aplicarían para los raros casos en que las empresas deciden, la mayoría de las veces en forma anónima y alterando los hechos, efectuar las consultas respectivas a este organismo.

106 Shingler (2013), p. 556. A su vez, también da cuenta de los eventuales problemas de establecer un sistema de regulación a través de una regla, pp. 556-557.

107 Al respecto, PACINI (2012), p. 572. Ver también SHINGLer (2013), p. 546, de acuerdo con quien ésta no sería una verdadera defensa, sino que más bien otorgaría la oportunidad (la autora habla de safe harbor término común en el lenguaje jurídico angloamericano) para que las empresas prueben que el pago no se efectuó con una intención corrupta. De acuerdo a la autora, si la persecución logra acreditar el ánimo corrupto, se excluiría la buena fe del pago.

108 PACINI (2012), p. 572. Información adicional del caso se puede extraer en la web: http://www.justice. gov/criminal-fraud/case/united-states-sec-v-metcalf-eddy-inc-court-docket-number-99-cv-12566-ng.
} 
la empresa para la obtención del negocio no puedan ser consideramos como actos de corrupción en la medida en que se hayan efectuado con el objeto de permitir la negociación respectiva dentro de los márgenes que permite el ordenamiento jurídico extranjero respectivo. Así, por ejemplo, los gastos necesarios para un conocimiento acabado del producto y su producción no debieran ser considerados como incompatibles con intereses que representa el funcionario si de lo que se trata es de elegir la mejor oferta. Las mismas reglas del juego relativas a la obtención de tales negocios permiten tales gastos. Distinto es el caso de que tales gastos excedan los meramente necesario para una toma de decisión informada, como, por ejemplo, gastos excesivos de entretenimiento, favores personales, productos ajenos al negocio y cuyo beneficiario sea quien debe tomar la decisión o relacionados al mismo, etc. En tales casos el gasto deja de ser necesario para la ejecución de su labor y pasa a ser un verdadero soborno para incidir en un eventual abuso del poder decisorio del funcionario.

Como se desprende de la breve descripción que se ha efectuado de la FCPA, la tendencia internacional en la actualidad para la prevención de la corrupción en el ámbito de las transacciones comerciales internacionales es a establecer prohibiciones relativamente amplias y reconocer una serie de factores que deben ser tenidos en cuenta, relativos principalmente a la realidad local, pero también vinculados a las reglas del juego en el ámbito económico respectivo, que permitirían determinar cuándo se estaría frente a un acto de corrupción y cuándo, por el contrario, a conductas permitidas.

Ahora, si bien no cabe duda de que la corrupción puede poner en entredicho una gran variedad de intereses en el ámbito económico, esto no significa que se pretenda proteger todos estos a través del Derecho Penal. A éste no le corresponde, por ejemplo, proteger las meras condiciones para el desarrollo económico de un país, a través de la prohibición de conductas que puedan incidir en la disminución de la inversión extranjera ${ }^{109}$. Si bien es cierto que se ha sostenido que la corrupción podría minar la confianza necesaria para fomentar la inversión, no sería éste un interés digno de protección para el Derecho Penal.

Ahora, si se analiza la potencialidad lesiva del cohecho a funcionarios públicos extranjeros, se podrá constatar que la preocupación que está detrás de la criminalización de esta conducta tendría que ver más bien con evitar los efectos distorsionadores de la competencia económica que podría traer aparejada. En suma, lo que se pretende proteger por esta prohibición son ciertas expectativas de los competidores en su trato con los funcionarios públicos extranjeros, en forma tal que las condiciones para la obtención o el mantenimiento de un

109 En forma similar, FElJOO (2009), p. 5, de acuerdo con quien el Derecho Penal económico no puede ser entendido como Derecho económico que se sirve de las penas para conducir la economía. 
negocio no se vean desvirtuadas por actos de corrupción que incidan en que unos generen ventajas comparativas ilícitas por sobre otros. Desde la perspectiva de la protección de la competencia, lo que interesa ahora es la protección de expectativas mínimas de participación y acceso a los negocios frente a ataques que parecen especialmente intolerables.

\section{Conclusión}

A modo de conclusión, sólo queda por señalar que los desafíos que se presentan para el Derecho Penal no son pocos. Como ha quedado de manifiesto, una respuesta adecuada a este fenómeno exige considerar su potencialidad lesiva en toda su extensión. No basta, entonces, con la prohibición de aquellos actos que puedan poner en entredicho el correcto funcionamiento de la función pública sin tomar en cuenta aquella gama de comportamientos considerados como especialmente graves y que, además, pueden afectar intereses vinculados con las posibilidades de participación en el ámbito económico. Ésta es una buena razón, por ejemplo, para examinar, al menos, la necesidad de incriminar actos de corrupción que puedan manifestarse en el ámbito exclusivamente privado, en la medida en que tales conductas puedan afectar seriamente las condiciones esperadas para la competencia.

Pero, a su vez, ha quedado en evidencia que la corrupción ya no puede enfrentarse únicamente como un fenómeno local sin atender a la dimensión global o trasnacional de la misma. A través del análisis de los principales problemas que se han presentado para la práctica estadounidense se ha podido detectar una serie de aspectos que reflejan la complejidad del fenómeno analizado. Como se pudo observar a través de la detección de espacios de ambigüedad en la prohibición del soborno a funcionarios públicos extranjeros de acuerdo a la FCPA, definir qué debe ser entendido como corrupción, o, más bien, por actos de corrupción, no es una tarea fácil, por lo que resulta imperiosa la necesidad de un mayor desarrollo y delimitación de este concepto por parte de la doctrina penal.

\section{BiBLIOGRAFÍA CITADA}

Abed, George T. y Davoodı, Hamid R., (2002): "Corruption, Structural Reforms, and Economic Performance in the Transition Economies", en: ABED, George T. y Sanjeev, Gupta (Editores), Governance, Corruption and Economic Performance (Washington, International Monetary Fund), pp. 489 y ss.

Ades, Alberto y Dı Tella, Rafael (2010): "The New Economics of Corruption: A Survey and Some New Results", en: Political Studies, XLV, 1997.

AIDT, Toke S. (2003): "Economic Analysis of Corruption: A Survey", en: The Economic Journal ( $\mathrm{N}^{\circ} 491$, vol. 113) 
Alcale Sánchez, María (2014): "La lucha contra la corrupción en el ámbito supranacional y su incidencia en el Código Penal español", en: Diritto penale contemporáneo ( $\left.\mathrm{N}^{\circ} 3-4\right)$.

Alonso, José Antonio y Garcimartín, Carlos (2011): "Causas y consecuencias de la corrupción: una revisión de la literatura", en: Alonso, José Antonio y Mulas-Granados, Carlos (Directores), Corrupción, cohesión social y desarrollo. El caso de Iberoamérica (México DF, Fondo de Cultura Económica).

Álvarez, Silvina (2007): "Corrupción y correcciones políticas", en: Zapatero, Virgilio (Compilador), La corrupción (México DF, Ediciones Coyoacán).

ArtazA, Osvaldo (2016): "La utilidad del concepto de corrupción de cara a la delimitación de la conducta típica en el delito de cohecho", en: Política Criminal ( $\left.\mathrm{N}^{\circ} 21\right)$.

Balmaceda, Gustavo y Castro, Carlos (2015): Corrupción y delitos contra la administración pública (Santiago, Librotecnia).

Bautista, Oscar Diego (2014): “Globalización y corrupción. Previniendo la corrupción en Iberoamérica mediante la ética pública en los albores del siglo XXI", en: Dilemata (año 6, No 15).

Benito SÁnchez, Carmen (2012): El delito de corrupción en las transacciones comerciales internacionales (España, lustel).

Bolea BARDón, Carolina (2013): "El delito de corrupción privada. Bien jurídico, estructura típica e intervinientes", en: In Dret ( $\left.\mathrm{N}^{\circ} 2\right)$.

BRAGUINSKY, Serguey (1996): "Corruption and Schumpeterian Growth in Different Economic Environments", en: Contemporary Economic Policy (vol. XIV, julio).

Carnevali Rodríguez, Raúl (2014): "Hacia un injusto penal de la criminalidad organizada. Una propuesta a modo de lege ferenda", en: Revista de Derecho de la Universidad Católica del Norte (año 21, № 2).

Castaldo, Andrea y Naddeo, Marco (2010): II denaro sporco. Prevenzione e repressione nella lotta al riciclaggio (Padua, Cedam)

Castresana Fernández, Carlos (2004): "Corrupción, globalización y delincuencia organizada", en: RodríGuez García, Nicolás y Fabián Caparrós, Eduardo (Coordinadores), La corrupción en un mundo globalizado: análisis interdisciplinar (Salamanca, Ratio Legis Librería Jurídica).

Chandler, Raymond (1990): El sueño eterno (Madrid, Debate).

CRITES, D. Michael (2012): "The Foreign Corrupt Practices Act at Thirty-Five: A Practitioner's Guide", en: Ohio State Law Journal (vol. 73:5).

De la Cuesta Arzamendi, José Luis y Blanco Cordero, Isidoro (2002): "La criminalización de la corrupción en el sector privado: ¿asignatura pendiente 
del Derecho Penal español", en: Diez Rıpoltés, José Luis (Coordinador). La ciencia del Derecho Penal ante el nuevo siglo. Libro Homenaje al Dr. José Cerezo Mir (Madrid, Tecnos).

De la Cuesta Arzamendi, José Luis (2003): "Iniciativas internacionales contra la corrupción", Eguzkilore, en: Cuaderno del Instituto Vasco de Criminología ( $\left.\mathrm{N}^{\circ} 17\right)$.

Díaz y García Conlledo, Miguel (2007): "El Derecho Penal ante la corrupción política y administrativa", en: ZAPATERO, Virgilio (Compilador), La corrupción (México DF, Ediciones Coyoacán).

Dı NıcolA, Andrea (2002): "La criminalitá economica organizzata: implicazioni di politica penale", en: Rivista Trimestrale di Diritto Penale dell'Economia.

Dreher, Axel y Schneider, Friedrich (2010): "Corruption and the Shadow Economy: An Empirical Analysis", en: Public Choice, 144.

FabiÁn CAPARRós, Eduardo (2010): “La corrupción de funcionario público extranjero en el Derecho Penal chileno a la luz del Convenio de la OCDE de 1997 (aspectos sustantivos)", en: Cheyre, Juan Emilio; Olivares Tramón José Miguel, y Rodrícuez García, Nicolás (Coordinadores), Chile en el Club de los países desarrollados (España, Editorial Pontificia Universidad Católica de Chile).

Faraldo Cabana, Patricia (2001): "Hacia un delito de corrupción en el sector privado", en: Estudios penales y criminológico ( $\left.\mathrm{N}^{\circ} 23\right)$.

Feijoo SÁnchez, Bernardo (2009): "Imputación objetiva en el Derecho Penal económico y empresarial. Esbozo de una teoría general de los delitos económicos", en: InDret ( $\left.\mathrm{N}^{\circ} 2\right)$.

Fernández Cruz, José Ángel (2000): “La 'empresa criminal': Los 'delitos de comercio' ilícito como factor de aparición del fenómeno del 'blanqueo de capitales'", en: Revista de Estudios Criminológicos y Penitenciarios ( $\mathrm{N}^{\circ} 5$ ).

FerRAJOl, Luigi (2009): "Criminalidad y globalización", en: CarbonelL, Miguel y VÁsQuez, Rodolfo (Compilador), Globalización y Derecho (Quito, Ministerio de Justicia y Derechos Humanos).

Flores GiméneZ, Fernando (2014): “Democracia interna y participación ciudadana como mecanismos de control de la corrupción", en: Nieto Martín, Adán y Maroto Calatayud, Manuel (Directores), Public Compliance. Prevención de la corrupción en administraciones públicas y partidos políticos (Cuenca, Ediciones de la Universidad de Castilla-La Mancha).

GÓmez, Carlos Mario (2007): "El análisis económico de la corrupción", en: ZAPATERO, Virgilio (Compilador), La corrupción (México DF, Ediciones Coyoacán). 
Gómez-Jara Díez, Carlos (2008): "Corrupción en el sector privado: ¿competencia desleal y/o administración desleal?, en: Revista cuatrimestral de las Facultades de Derecho y Ciencias Económicas y Empresariales ( $\left.N^{\circ} 74\right)$.

Green, Stuart (2013): Mentir, hacer trampas y apropiarse de lo ajeno. Una teoría moral de los delitos de cuello blanco (Madrid, Barcelona, Buenos Aires, Sao Paulo, Marcial Pons).

Gupta, Sanjeev; Davoodi, Hamid, y Alonso-Terme, Rosa (2002): “Does Corruption Affect Income Inequity and Poverty?, en: Abed, George T. y SAnjeev, Gupta (Editores), Governance, Corruption and Economic Performance (Washington, International Monetary Fund).

Haller, Dieter y Shore, Cris (Editores) (2005), Corruption. Anthropological Perspectives, (Londres, Pluto Press).

Hefrernan, William C. y Kleinig, John (Editores) (2004): Private and Public Corruption, (Lanham, Rowman and Littlefield Publishers).

Hernández Basualto, Héctor (2010), "El delito de enriquecimiento ilícito de funcionarios en el Derecho Penal chileno", en: Revista de Derecho de la Pontificia Universidad Católica de Valparaíso (vol. XXVII, $2^{\circ}$ semestre).

Hodgson, Geoffrey M. y JIANG, Shuxia (2007): "The economics of corruption and the corruption of economics: an institutionalist perspective", Journal of Economic Issue (vol. XLI, No 4 ).

Holmes, Leslie (2015): Corruption. A very short Introduction (Oxford, Oxford University Press).

Johnston, Michael (2014): Corruption, contention and reform. The power of deep democratization (Cambridge, Cambridge University Press).

KINDHÄUSER, Urs (2007): "Presupuestos de la corrupción punible en el Estado, la economía y la sociedad, Los delitos de corrupción en el Código Penal alemán", en: Política Criminal (año 1, № 3).

Koemler, Mike (2010): "The Foreign Corrupt Practices Act in the Ultimate Year of Its Decade of Resurgence", en: Indiana Law Review, (vol. 43).

LaUdatı, Antonio (2003): "Criminalità organizzata e riciclaggio", en: Patalano, Vincenzo (Editor), Nuove strategie per la lotta al crimine organizzato transnazionale (Turín, Giappichelli), p. 217.

Lo Monte, Elio (2003): "Ecomafia: il controllo penale tra simbolicità ed effettività", en: Patalano, Vincenzo (Editor), Nuove strategie per la lotta al crimine organizzato transnazionale (Turín, Giappichelli).

Loughman, Brian P. y Sibery, Richard A. (2011): Bribery and Corruption: Navigating the Global Risks (Kindle Ed.). 
Malem SeÑa, Jorge (2007): "Corrupción, racionalidad y educación moral", en: ZAPATERO, Virgilio (Compilador), La corrupción (México DF, Ediciones Coyoacán).

Mauro, Paolo (1997): "The Effect of Corruption on Growth, Investment and Government Expenditure: A Cross-Country Analysis", en: Corruption and the Global Economy, Institute of International Economics.

MONTANARI, Marco (2012): "La normativa italiana in materia di corruzione al vaglio delle istituzioni internazionali", en: Diritto penale contemporáneo ss. Disponible en: http://www.penalecontemporaneo.it/upload/1341134726Montanari\%20-\%20 DPC.pdf

Morales Quiroga, Mauricio (2009): "Corrupción y democracia, América Latina en perspectiva comparada", en: Gestión y Política Pública (vol. XVIII, № 2).

Mulas-Granados, Carlos (2011): "Indicadores de corrupción en Iberoamérica", en: Alonso, José Antonio y Mulas-Granados, Carlos (Directores), Corrupción, cohesión social y desarrollo. El caso de Iberoamérica (México DF, Fondo de Cultura Económica).

Muriel Patino, María Victoria (2004): "Aproximación macroeconómica al fenómeno de la corrupción", en: RodríGuez García, Nicolás y Fabián Caparrós, Eduardo (Coordinadores), La corrupción en un mundo globalizado: análisis interdisciplinar (Salamanca, Ratio Legis Librería Jurídica).

Nieto Martín, Adán (2003): "La corrupción en el comercio internacional (o de cómo la americanización del Derecho Penal puede tener de vez en cuando algún efecto positivo)", en: Revista Penal (№ 12).

Oliver Calderón, Guillermo (2003): "Ultimas modificaciones en la regulación del delito de cohecho (ley No 19.829 de 1999)", en: Revista Chilena de Derecho (vol. 30, № 1).

Oliver Calderón, Guillermo (2004): "Aproximación al delito de cohecho", en: Revista de Estudios de la Justicia ( ${ }^{\circ} 5$ ).

PACINI, Carl (2012): "The Foreign Corrupt Practices Act: Taking a bite out of bribery in international business transactions", en: Fordham Journal of Corporate \& Financial Law (vol. 17, Issue 2).

Pelizzo, Riccardo y Stapenhurst, Frederick (2014): Corruption and Legislatures (Nueva York, Taylor and Francis).

Plantamura, Vito (2007): "Ecomafia, reati associativi e diritto penale dell'economia", en: Rivista trimestrale di diritto penale dell'economia.

Politoff, Sergio; Matus, Jean Pierre, y Ramírez, María Cecilia (2004): Lecciones de Derecho Penal chileno. Parte Especial, $2^{\text {a }}$ edición (Santiago, Editorial Jurídica de Chile). 
Richard, Samuel B., (2014): "To Bribe a Prince: Clarifying Foreign Corrupt Practices Act Through Comparisions to the United Kingdom's Bribery Act of 2010", en: Boston College International and Comparative Law Rewiew (vol. 37/2).

Rodríguez CollaO, Luis (2004): "Delimitación del concepto penal de corrupción", en: Revista de Derecho de la Pontificia Universidad Católica de Valparaíso (vol. XXV).

Rodríguez Collao, Luis y Ossandón Widow, Magdalena (2008): Delitos contra la función pública, $2^{\mathrm{a}}$ edición (Santiago, Editorial Jurídica de Chile).

Rose-Ackerman, Susan (1999): Corruption and Goverment. Causes, consequences, and reform (New York, Cambridge University Press).

Rose, Cecily (2015): International anti-corruption norms (Oxford, Oxford University Press).

SÁnChez Bernal, Javier (2010): "La corrupción en el sector privado: debate en torno a su inclusión en el Código Penal", en: Cuadernos del Tomás ( $\mathrm{N}^{\circ} 2$ 2).

Sánchez García de la Paz, Isabel (2008): "Problemas de legitimidad de una respuesta excepcional frente a las organizaciones criminales", en: CANCIO Melı́, Manuel y Pozuelo Pérez, Laura (Coordinadores), Política criminal en vanguardia (Cizur Menor, Thomson Civitas).

Sanz, Ismael; Acevedo, Paloma, y Guerrero, Alejandro (2011): "Educación, cohesión social y corrupción", en: Alonso, José Antonio y Mulas-Granados, Carlos (Directores), Corrupción, cohesión social y desarrollo. El caso de Iberoamérica (México DF, Fondo de Cultura Económica).

Seligson, Mitchell A. (2006): "The Measurement and Impact of Corruption Victimization: Survey Evidence from Latin America", en: World Development (vol. 34, $\mathrm{N}^{\circ}$ 2).

Seminara, Sergio (1995): "Aspectos problemáticos en materia de insider trading", (Traducc. C. Suárez González), en: AA.VV., Hacia un Derecho Penal económico europeo. Jornadas en honor del Prof. Klaus Tiedemann (Madrid, Boletín Oficial del Estado).

SHINGLER, Elizabeth S. (2013): "The Foreign Corrupt Practices Act: A new approach to the reasonable and bona fide expenditure defense", en: Brook. J. Corp. Fin. \& Com. L. (vol. 7).

SHORE, Cris y Haller, Dieter (2005): "Introduction-sharp practice: anthropology and the study of corruption", en: Haller, Dietery y SHORE, Cris (Editores), Corruption. Anthropological Perspectives (Londres, Pluto Press).

Solís, Luis Guillermo y Rojas Aravena, Francisco (Editores) (2008): Crimen organizado en América Latina y el Caribe (Santiago, Catalonia). 
Sото, Raimundo (2003): "La corrupción desde una perspectiva económica", en: Estudios Públicos ( $\mathrm{N}^{\circ} 89$ ).

Stein, Alex (2012): "Corrupt intentions: bribery, unlawful gratuity, and honestservices fraud", en: Law and Contemporary Problems (vol. 75).

Strauss, Emily N. (2013): "Easing out' The FCPA facilitation payment exception", en: Boston University Law Review (vol. 93).

SzCZARAnsky, Clara (2000): "El Consejo de Defensa del Estado y el control de la criminalidad organizada y del lavado de dinero", en: Politoff, Sergio y MATUS, Jean Pierre (Coordinadores), Gran criminalidad organizada y tráfico ilícito de estupefacientes (Santiago, Conosur).

SzCZARANSKI, Clara (2011): Un asunto criminal contemporáneo. Rol de las empresas, responsabilidad penal de las personas jurídicas y corrupción (Santiago, Editorial Jurídica de Chile).

TANZI, Vito (2002): "Corruption Around the World: Causes, Consequences, Scope, and Cures", en: Abel, George T. y SAnjeev, Gupta (Editores), Governance, Corruption and Economic Performance, (Washington, International Monetary Fund).

TanzI, Vito y Davood, Hamid (2002): "Corruption, Growth, and Public Finances", en: Abed, George T. y SAnjeEv, Gupta (Editores), Governance, Corruption and Economic Performance (Washington, International Monetary Fund).

WeISS, David C. (2009): "The Foreign Corrupt Practices Act, SEC disgorgement of profits, and the evolving international bribery regime: Weighing proportionality, retribution, and deterrence", en: Michigan Journal of International Law (vol. 30).

WestBRook, Amy Deen (2011): "Enthusiastic Enforcement, informal legislation: The unruly expansión of the Foreign Corrupt Practices Act", en: Georgia Law Review (vol. 45).

Yadav, Vineeta (2011): Political Parties, Business Groups, and Corruption in Developing Countries (Nueva York, Oxford University Press).

ZalaQuet, José (2011): "Conflicto de intereses: normas y conceptos", en: Anuario de Derechos Humanos de la Universidad de Chile.

ZúNíga Rodríguez, Laura (2009): Criminalidad organizada y sistema de Derecho Penal. Contribución a la determinación del injusto penal de organización criminal (Granada, Comares).

ZyLA, Eric M., (2011): "Foreign Corrupt Practices Act: A brief overview", en: Ankara Bar Review (vol. 4). 